\title{
LA FORMACIÓN DE COMPAÑIIAS COMERCIALES EN ZAMORA EN EL SIGLO XVI (1575-1600)
}

\section{Trading Companies Foundation in the City of Zamora in the Sixteenth Century (1575-1600)}

Francisco Javier LORENZO PINAR

Universidad de Salamanca

Correo-e: lopinar@usal.es

RESUMEN: El presente artículo tiene por objeto reconstruir las condiciones bajo las cuales se fundaron las compañías comerciales en la urbe zamorana, tratando de delimitar la categoría socio-profesional de sus socios, su objeto y capital social, su período de vigencia y las zonas geográficas de actuación. Así mismo intentará delinear las posibles concomitancias o rasgos distintivos frente a otras sociedades mercantiles españolas y comprobar algunas afirmaciones que se han efectuado acerca de la actividad comercial de la ciudad durante el Quinientos. Por otro lado, este estudio supone una contribución a una temática escasamente abordada para esta centuria en zonas del interior peninsular.

Palabras clave: Sociedades comerciales, compañías, mercaderes, pescado, Zamora, España, siglo XVI.

ABSTRACT: This paper tries to reconstitute the conditions for the foundation of the trading companies in the city of Zamora (northwest of Spain) in the Sixteenth Century. It studies the socio-professional category of the associates, their functions, their contributions, the duration of the companies and their geographical areas of action. It'll also delineate the distinctive features or possible parallelisms with others Spanish societies and it'll try to verify some affirmations about the commercial activity of Zamora during this period. This article supposes a contribution to a 
subject scarcely studied for the interior places of the Iberian Peninsula in the Sixteenth Century.

Key words: Trading societies, companies, merchants, fish, Zamora, Spain, Sixteenth Century.

\section{INTRODUCCIÓN}

Aunque los estudios e investigaciones sobre las compañías mercantiles castellanas se han ido incrementando desde la década de 1960, fecha en la que Manuel Basas Fernández se lamentaba de su escasez, en la actualidad, a tenor de la opinión de Agustín González Enciso queda mucho por hacer en el ámbito del comercio interior ${ }^{1}$. La balanza historiográfica sigue inclinada hacia las zonas costeras y de manera especial hacia estudios centrados en el siglo $\mathrm{xvIII}^{2}$. Esta escasez de análisis acerca del comercio interno y sus redes, así como la orientación de los trabajos hacia el Setecientos, se presenta como un fenómeno que mantiene paralelismos con el país vecino ${ }^{3}$. El presente trabajo pretende constituir una aportación hacia el lado de la balanza más desfavorecido y hacia un comercio local que Hilario Casado ha calificado como «el gran desconocido de la historia económica española» ${ }^{4}$.

Si bien la constitución de compañías en la urbe zamorana a lo largo del siglo XVI afectó a distintos ámbitos de la actividad productiva e impositiva, tales como

1. Basas Fernández, M.: «Contratos de compañías mercantiles castellanas del siglo XVI», Revista de Derecho Mercantil, 30 (1960), pp. 375-412 y GonZÁlez EnCISO, A.: «El comercio en la España interior durante la época moderna», Obradoiro de Historia Moderna, 17 (2008), pp. 15-42.

2. Ver García-BAquero GonzÁlez, A.: Cádiz y el Atlántico (1717-1778). (El comercio colonial español bajo el monopolio gaditano). Tomo I. Cádiz, 1976; Franch Benavent, R.: Crecimiento comercial y enriquecimiento burgués en la Valencia del siglo XVIII. Valencia, 1986; SÁNCHEZ GONZÁLEZ, R.: «Burguesía mercantil: mercaderes y comerciantes en Toledo en el siglo XVIII» en ARANDA PÉREZ, J. F.: Burgueses o ciudadanos en la España Moderna. Cuenca, 2003, pp. 109-143. Melón JiméNEZ, M. Á.: Los origenes del capital comercial y financiero en Extremadura. Compañias de comercio y banqueros de Cáceres (1773-1836). Cáceres, 1992; Gómez Carrasco, C. J.: Familia y capital comercial en la Castilla meridional: la comunidad mercantil en Albacete (1700-1835). Madrid, 2009, entre otros. Para el interior, Angulo Morales, A.: Del éxito en los negocios al fracaso del consulado: la formación de la burguesía mercantil de Vitoria (1670-1840). Vitoria, 2000 o los artículos sobre Sevilla, Cuenca y Segovia en Pérez, B.; Rose, S. V. y Clément, J. P. (dirs.): Des marchands entre deux mondes: pratiques et représentations en Espagne et en Amérique (XVe-XVIIIe siècles). París, 2007, pp. 133-156; 157-177 y $179-194$.

3. Freire Costa, L.: «Comércio e Família em Portugal. Séculos XVI-XVII» en SoAres Da Cunha, M. y Hernández Franco, J. (orgs): Sociedade, família e poder na Península Ibérica: elementos para una bistória comparativa. Lisboa-Murcia, 2010, p. 157.

4. «Comercio y nacimiento del Estado moderno en Castilla, siglos XV y XVI: algunas reflexiones a la luz de nuevas corrientes de investigación internacional». En Aragón en la Edad Media: el Estado de la Baja Edad Media: nuevas perspectivas metodológicas: sesiones de trabajo. Zaragoza, 1999, p. 62. 
la construcción ${ }^{5}$, el trabajo en los pisones ${ }^{6}$, el mundo textil ${ }^{7}$, el del curtido ${ }^{8}$, los servicios de abastecimiento o el cobro de diferentes rentas 9 , nos centraremos exclusivamente en el ámbito comercial dado que el mayor número de estas corporaciones estuvo íntimamente ligado a la comercialización de productos alimenticios. Por otro lado hemos utilizado el término genérico de compañía dado que se trata de la denominación otorgada por las escrituras notariales -en el 85 por ciento de los documentos- para referirse a este tipo de sociedades. El resto, aunque bajo otra designación, aluden a sociedades que contaron igualmente con la estructura propia de las compañías. Solo en un número de reducido de casos hallamos características inherentes a las comendas ${ }^{10}$.

Aunque hemos procedido al vaciado de todos los protocolos notariales del Archivo Histórico Provincial de Zamora referentes a individuos que residieron en la urbe y que redactaron ante escribano escrituras fundacionales calificadas de «asiento», «concierto», «concordia», «obligación» o fundación de «compañía», solo nos hemos centrado en el último cuarto de siglo ya que es el período en el cual se conserva la serie completa de escribanos. Se han localizado para estos años 85 escrituras fundacionales -ver apéndice- que nos servirán para marcar las principales

5. Archivo Histórico Provincial de Zamora [en adelante AHPZa], Protocolos Notariales [en adelante PN], leg. 528. 4-I-1588, fols. 1-2.

6. AHPZa, PN, leg. 657. 15-VI-1596, fol. 475.

7. AHPZa, PN, leg. 695. 15-X-1599, fols. 421-422; leg. 724. VIII-1599, fol. 453.

8. No aparece denominada como "compañía» sino como concierto «a pérdida o ganancia». AHPZa, PN, leg. 444. 19-X-1569, fol. 285.

9. AHPZa, PN, leg. 390, fols. 239-240; leg. 270. 6-XI-1675, fols. 693-696; leg. 459, fol. 459; leg. 423. VII-1588, fols. 98-99; leg. 481b. 29-IX-1584, fol. 689.

10. Fue el caso de la de Doña María de Guedeja que entregó 14.300 reales al mercader García Hernando para comerciar con paños seda, cera y azúcar. Al margen de esta situación encontramos algunos contratos denominados como compañías que mantienen rasgos propios de las comendas como los del Licenciado Antonio de Tapias de Vargas con el especiero Gaspar Núñez y su mujer Luisa Herrera; o de este mismo con el lencero Antonio Hernández para negociar con mercadurías de su ramo; la de Bartolomé Sánchez con el mercader Alonso Lagartero y su mujer María Guerra para cualquier trato lícito. En ellas solo los primeros citados aportan capital en metálico y exigen fianzas unilaterales a los profesionales que se van a dedicar a negociar el género. Para José Martínez Gijón estaríamos ante comendas que los escribanos tratan como compañías debido a la apariencia social de que se hallan revestidas. M. Basas Fernández utiliza en estos casos el término de «compañías comanditarias». AHPZa, PN, leg. 399. 12-III-1583, fols. 139-140; leg. 400. 27-VII1584, fols. 391-392; leg. 658. 1599, fol. 272; leg. 476. 3-VIII-1598, fols. 767-768. MARTínEz Gijón, J.: «La comenda en el Derecho Español. II. La comenda mercantil», Anuario de Historia del Derecho Español, T. XXXVI, 1966, pp. 379-476; Basas Fernández, M.: Art. cit. p. 383; Grenier, J-Y.: L'économie d'Ancien Régime: un monde de l'échange et de l'incertitude. Paris, 1996, p. 93; IMBERT, J.: «Evolutión du régime juridique de l'enterprise». En CAVACIOCHI, S. (A cura di): L'impresa: industria, commercio, banca, secc. XIII-XVIII: Atti della "Ventiduesima Settimana di Studi». Firenze, 1991, pp. 61 y 66. 
tendencias en el ámbito de los negocios concertados en el marco la ciudad ${ }^{11}$. En cualquier caso se trata de un cifra inferior al número de compañías que realmente operaron en la urbe zamorana durante estas fechas ya que como sucedió en otras zonas y en distintos períodos de la Edad Moderna las sociedades no se siempre se registraron notarialmente ${ }^{12}$. Contamos con varias escrituras -cuentas, obligaciones, poderes, etc.- de compañías de las que carecemos de su contrato fundacional, e incluso alusiones a sociedades que habían venido funcionando durante años sin que aparezca su constitución ante el escribano ${ }^{13}$. Otras veces el acto notarial se materializó en ciudades distintas a los núcleos de procedencia de los socios ${ }^{14}$. Tampoco es posible ofrecer una cifra exacta de todas las compañías existentes en la urbe ante las dudas que nos plantean los documentos. Así, por ejemplo, desconocemos si cuando estos aluden a un determinado individuo y «compañía» $\mathrm{O}$ "compañeros» hacen siempre referencia a una sociedad de carácter comercial o no ${ }^{15}$.

\section{LA MASA SOCIAL}

Establecer la categoría socio-profesional de los socios de las compañías zamoranas resulta una tarea complicada ya que en veintiuna de las escrituras esta no se

11. En el caso de Barcelona para 1650-1720 Isabel Lobato ha encontrado 151 documentos y de ellos 101 están dedicados a compañías de comercio, únicas analizadas en nuestro caso; para el siglo Xvi Falah Hassan Abed Al-Hussein ha trabajado con 96 sociedades relativas a Medina del Campo; Jean- Philippe Priotti con 20 para Bilbao y José Ignacio Gómez Zorraquino con 17 para Aragón. Como se puede apreciar, se trata de un número elevado teniendo en cuenta la brevedad del período estudiado. Lobato Franco, I.: Compañias y negocios en la Cataluña preindustrial. Sevilla, 1995, pp. 34 y 72; AbED Al-Hussein, F. H.: «Las compañías o asociaciones de mercaderes», en LORENZO SANZ, E. (coord.): Historia de Medina del Campo y su tierra. Ange de las ferias. Decadencia de Medina. Vol. II. Medina del Campo, 1986, p. 193; GÓmEZ ZORRAQuino, J. I.: La burguesía mercantil en el Aragón de los siglos XVI y XVII (1516-1652). Zaragoza, 1987, p. 120; PRIOTTI, J-P.: Bilbao et ses marchands an XVIe siècle: genèse d'une croissance. Villeneuve-d'Ascq, 2004.

12. Alberto Angulo Morales señala, por ejemplo, que en Bilbao a partir de la aplicación de las ordenanzas del Consulado de 1737 la primera medida que fue tomada consistió en regularizar las compañías existentes obligando a los mercaderes a presentar copia notarial de ellas y algunos comerciantes manifestaron la inexistencia de contrato mercantil alguno ya que la sociedad se basaba en la mutua confianza que se dispensaban los socios. ANGUlo Morales, A.: «Los dilemas de la burguesía y el comercio vascos en la España Moderna. Un estado de la cuestión», en Aranda Pérez, J. F.: Op. cit., pp. 319-320 y LOBATO FRANCO, I.: «Reglamentación y práctica en las compañías mercantiles barcelonesas de la segunda mitad del siglo XVII», en MArTínez Shaw, C. (eds.): El derecho y el mar en la España moderna. Granada, 1995, p. 63.

13. AHPZa, PN, leg. 360. 30-VI-1583, fols. 335-336; leg. 361. 18-VII-1584, fol. 394; leg. 400. 8-VII-1584, fols. 327-328; leg. 517. 9-XII-1593, fol. 962.

14. La compañía de Antonio Tabao, Esteban Petio y Antonio Bisel, vecinos de Medina del Campo, se disolvió documentalmente en Zamora. La de Alonso de la Peña y Gaspar Sánchez, vecinos de Peñaranda, destinada al trato de pescado, escrituró su fundación en la urbe zamorana. AHPZa, PN, leg. 541. 7-VIII-1599, fol. 435; leg. 565. 15-XI-1588, fols. 733-734; leg. 741. 30-XII-1600, fols. 984-985.

15. AHPZa, PN, leg. 610. 18-II-1594, fol. 138. 
indicó para ninguno de los individuos. En aquellas que se señaló se aprecia cómo en nueve de cada diez casos aparecen miembros citados como "mercaderes» ${ }^{16}$. También participaron un lencero y un especiero, probablemente ligados a este sector mercantil. Todos ellos podríamos identificarlos, por el capital en efectivo aportado, como miembros de la pequeña y mediana «burguesía» aunque faltan estudios prosopográficos y locales al respecto ${ }^{17}$. Las sociedades comerciales zamoranas estuvieron integradas fundamentalmente por varones. La limitada participación de las mujeres -presentes en 15 de las compañías- estuvo representada por las esposas de los mercaderes que actuaron conjuntamente con ellos; por viudas que decidieron continuar con el negocio de sus maridos aunque tan solo fuera de una manera temporal, es decir, hasta concluir las transacciones mercantiles pendientes, y por un reducido colectivo de nueve mujeres con iniciativa empresarial. Destaca el caso de Blanca de Bergas, quien llegó a aportar el segundo capital monetario más elevado de estas sociedades -26.000 reales-. La cifra moda de los socios -ver cuadro 1- que las componían solía ser de dos, una tendencia habitual en otras zonas $^{18}$. Una mayor presencia de compañeros solía responder habitualmente a la búsqueda de un incremento en el capital en efectivo de la compañía.

Cuadro 1. Número de socios por compañía. Zamora (1575-1600)

\begin{tabular}{|c|c|}
\hline Número de socios & Total de compañías \\
\hline 2 & 61 \\
\hline 3 & 19 \\
\hline 4 & 5 \\
\hline
\end{tabular}

En una de cada tres sociedades los compañeros procedieron de la ciudad o de los pueblos de Zamora, aunque predominaron aquellas en las que hubo una

16. A diferencia de Barcelona no existió una abundante representación de artesanos. Estuvo limitada a un tejedor y a un sedero. LOBATO Franco, I.: Op. cit. p. 247.

17. Otros criterios clasificatorios prefieren distinguir simplemente entre grandes y pequeños mercaderes, encontrándose la mayoría de los zamoranos entre los segundos, e incluso son reticentes a la utilización del término «burgués»-caso de Máximo Diago-. El problema para aproximarnos a estos individuos, como ya señalara J. N. Ball, es que se conocen los nombres de miles de mercaderes y de las grandes familias, pero faltan estudios al detalle de los más modestos. FENICIA, G.: «Mercanti, commercianti e uomini d'affari in Italia al tempo dei Re Cattolici», en CASADO Alonso, H. y GARCíABAquero, A. (eds.): Comercio y hombres de negocios en Castilla y Europa en tiempos de Isabel la Católica. Madrid, 2007, p. 92; BALL, J. N.: Merchants and Merchandises. The expansion of trade in Europe. 1500-1630. Londres, 1977, pp. 106; Diago Hernando, M.: «Los hombres de negocios en la ciudad de Soria durante el siglo XVII», Hispania, 205 (2000), p. 481.

18. Lobato Franco, I.: Op. cit. p. 38. 
participación de zamoranos con individuos procedentes de diferentes lugares de Galicia -en el 57,9 por ciento de los casos-. Estos últimos residían fundamentalmente en las zonas portuarias de Bayona, Villamayor, Vigo, Pontevedra o Lugo. En el resto encontramos personas de Peñaranda de Bracamonte, Tordesillas, Medina del Campo y Salamanca ${ }^{19}$. A veces se exigió contractualmente a alguno de los compañeros zamoranos «tomar vecindad» o residir en las zonas portuarias de Galicia o en diferentes partes de Portugal -Viana, Oporto o Lisboa ${ }^{20}$ - para adquirir azúcar, pescado, especias y palo de Brasil21. Ignoramos si se buscaba con esta exigencia conferir una cierta continuidad al negocio con un factor fijo en la zona o garantizar en mayor medida el suministro con alguien que viviese en el lugar de procedencia del género. Lo cierto es que quienes establecieron este tipo de cláusulas contractuales no mantuvieron empresas por un largo periodo de tiempo. Al socio estante en el reino vecino se le podía compensar con una cuantía monetaria obtenida de gravar con una pequeña cantidad cada carga de mercancía enviada a Zamora ${ }^{22}$. Este agente debía conseguir el género «a los precios» $\mathrm{o}$ «a los tiempos y sazones que le pareciere», es decir, las adquisiciones quedaban a su libre albedrío aunque se presuponía que no debía incurrir en arbitrariedades o decisiones perjudiciales para la sociedad ${ }^{23}$. Si no asistía a los mercados a aprovisionarse, las pérdidas serían a su cargo o se le impondría una multa por cada carga de género que dejase de enviar ${ }^{24}$. Aunque la franqueza debía presidir las relaciones entre los socios no faltaron cláusulas que recordaban a uno de ellos cómo debía negociar: «fiel y verdaderamente lo que tratare y ha[bía] de tener cuidado y rectitud de manera

19. Si atendemos a la triple división de las redes de comercio de las que nos habla Hilario Casado Alonso -local, regional e internacional-, en Zamora predominaron las dos primeras manteniendo relaciones porcentualmente minoritarias con Portugal. CASADO AlONSO, H.: «El comercio burgalés y la estructuración del espacio económico español a fines de la Edad Media», en Itinerarios medievales e identidad hispánica: XXVII Semana de Estudios Medievales. Navarra, 2001, p. 335 y «Crecimiento económico y redes de comercio interior en la Castilla septentrional (siglos XV y XVI)», en FORTEA PÉreZ, J. I. (ed.): Imágenes de la diversidad: el mundo urbano en la Corona de Castilla (ss. XVI-XVIII). Santander, 1997, p. 285.

20. AHPZa, PN, leg. 150. 22-VI-1575; leg. 396. 31-III-1579, fol. 215; leg. 520. 2-VI-1596, fols. 408-409; leg, 696. 24-XII-1600, fol. 643.

21. Hilario Casado subraya cómo Portugal se convirtió en el siglo Xvi en un espacio que suscitó la atención de las redes comerciales castellanas. Las especias africanas y asiáticas canalizadas a través del puerto lisboeta incrementarían la importancia de esta ciudad y el azúcar y los colorantes brasileños estarían, durante la segunda mitad de la centuria, controlados en gran medida por comerciantes del norte del país. CASADO ALONSO, H.: «Los flujos de información en las redes comerciales castellanas de los siglos XV y XVI», Investigación de Historia Económica, 10 (2008), p. 43.

22. Antonio de Villalpando recibía 3 reales por cada carga. AHPZa, PN, leg. 396. 31-III-1579, fol. 215.

23. AHPZa, leg. 396. 29-I-1579, fol. 412; leg. 441. 14-III-1578, fols. 178-179.

24. En el contrato entre Bernardo Rodríguez, vecino de Zamora, y Alonso González, vecino de La Guardia, se estableció en 50 reales la carga. AHPZa, PN, leg. 397. 31-VII-1581, fol. 399. 
que siempre trat[as]e verdad $»^{25}$. Tampoco esta mutua confianza estaba desligada de la exigencia de fiadores como garantes del capital monetario encomendado para las transacciones o de medidas preventivas, como la de que un socio tuviese en su posesión el arca con el dinero y el otro las llaves ${ }^{26}$.

$\mathrm{Al}$ margen de los socios y factores, estas sociedades contaron con mozos a su servicio y otras personas que "ayudaban al beneficio de las dichas mercadurías», sin que la documentación explicite en qué consistía realmente su misión. Estos últimos solían ser gente residente en los lugares de procedencia de los géneros ${ }^{27}$. También dieron trabajo a familiares de los socios, especialmente a los hijos, a quienes se les encomendaba la adquisición de parte del género ${ }^{28}$. En líneas generales estos dependientes de la compañía solían ser pagados del monto de los beneficios antes del reparto entre los asociados. En ocasiones uno de los socios podía estar encargado de parte de la manutención de estos obreros. Así, por ejemplo, se decidió en la de pescados de Francisco Alonso, Pedro Gumiel y Juan Pérez, este último vecino de Tordesillas. El mozo percibiría 400 reales anuales, además de los zapatos y calzas que rompiese a costa de los beneficios, además de la comida -proporcionada por Juan- cada vez que fuese a Pontevedra ${ }^{29}$. También recurrían para llevar a cabo sus actividades a arrieros o recueros que transportaban el pescado, la cera y el azúcar desde Galicia, abonándoseles una cantidad conforme al precio de la mercancía. Luis de Valencia, zamorano, contrató los servicios de Antonio Fernández y Juan Rodríguez, portugueses, de la tierra de Braganza, quienes se comprometieron a realizar el traslado de las mercancías antes de Pascua Florida con nueve mulos, «sin faltar camino alguno ni holgar en los puertos más de dos días» ${ }^{30}$. El precio se estipulaba en función del peso por arrobas salvo para los sábalos cuyo pago a los recueros solía realizarse habitualmente por $\operatorname{cargas}^{31}$. Bartolomé de Villalpando

25. La misma exigencia encontramos en otras compañías donde había un socio capitalista y otro que ponía su trabajo, caso de la de lienzos entre el licenciado Antonio de Tapias de Vargas y Antonio Hernández, lencero. AHPZa, PN, leg. 22-VIII-1581, fols. 292-293; leg. 658. 30-III-1599, fol. 272.

26. AHPZa, PN, leg. 696. 13-XI-1600, fol. 498.

27. AHPZa, PN, leg. 399. 16-VI-1583, fols. 303-304.

28. En la de Pedro Sánchez con Blanca de Bergas, el hijo de esta última se ocuparía de conseguir el sebo que se hubiere comprado para el abasto de la candelería acudiendo a las «partes y lugares» necesarios por cuenta de la compañía. AHPZa, PN, leg. 485A. 26-VII-1589, fols. 787-789.

29. En el contrato de Rodrigo Alderite con el mercader de pescados Pedro de Quirós para que trabajase como su mozo durante cuatro años, se le asignaron unos emolumentos similares: 440 reales anuales y la manutención. Estas cifras se encontraban muy por encima del salario de los criados domésticos, quienes cobraban unas cuatro veces menos. En este último caso la relación contractual se daría por finalizada si el mercader fallecía. AHPZa, PN, leg. 150. 22-VI-1575, fols. 301-302; leg. 444, fols. 809-810.

30. AHPZa, PN, leg. 478. 5-IX-1580, fol. 538.

31. Luis de Valencia estableció un precio de 3,5 reales por carga que sería pesada en el peso y casa de Juan de Astorga. Rodrigo Rodríguez, se obligó a traer pescado a Luis de Valencia desde Galicia 
estableció una relación contractual con el ordinario Bartolomé Clérigo, vecino de Bustavalle, jurisdicción del Marqués de Viana, en el reino de Galicia, para que «anduviese con seis u ocho rocines». Cobraría por cada carga -de once arrobas gallegas- 58 reales «y si alguna trajere pequeña entre ellas se la ha de pagar al respecto de lo que pesare» ${ }^{32}$. El socio residente en Zamora se encargaba de abonar los emolumentos en función de cómo lo «hubiere igualado» su factor gallego conforme a las cartas que presentase ${ }^{33}$. Antonio de Vergas, mercader zamorano, acordó con Juan Gómez, vecino de Torboes, jurisdicción de Pinel (Portugal) que con sus cuatro mulos realizase un camino cada tres semanas, tres días más o menos, yendo a los puertos de Portugal y Galicia tomando «mercado desde los lunes a las vísperas» para obtener «el mejor» pescado, «excepto si no lo hubiere, caso fortuito». Lo transportaría a razón de 4,5 reales la arroba -11 reales en el caso de la carga de sardina-. Los portazgos así como los gastos de embalaje (canastas, esteras y sogas) corrían a cargo del mercader, quien adelantaba un dinero al arriero y pagaba el resto a su llegada a Zamora ${ }^{34}$.

\section{LAS NORMAS DE ARTICULACIÓN INTERNA}

Los aspectos relacionados con las aportaciones realizadas al fondo de las compañías, la distribución de ganancias, la responsabilidad ante las deudas o la gestión de la contabilidad, al igual que en otras zonas, formaron parte habitual de las cláusulas constitutivas de las sociedades mercantiles zamoranas. A pesar de ello, resulta difícil, por ejemplo, reconstruir el capital en efectivo de cada una de las sociedades, ya que no siempre se indica en los documentos. Se podría realizar una aproximación en aquellas situaciones en las que se señala el expuesto por uno de los socios y los porcentajes de participación o pérdida por parte del resto de compañeros; sin embargo, existen varios problemas para su cuantificación. A veces se indicaba que uno de los socios participaría con «lo que fuera necesario» o «menester para el dicho trato y compañía» sin especificar cantidad alguna. En otras ocasiones la cifra reflejada en el contrato fue inferior a la real. Aunque aparece explícito el capital monetario de cada socio, se señalaba que si hiciera falta más se aportaría «pro-rata lo que fuere menester» ${ }^{35}$. Hemos de tener en cuenta igualmente que otros elementos que entraban a formar parte del capital social de la compañía resultan difíciles de precisar con exactitud, caso de los relacionados

a 62 reales la carga -de diez u once arrobas cada una- y llevar trigo a 25 reales cada tres fanegas. AHPZa, PN, leg. 478. 5-IX-1580, fol. 538; leg. 709. 4-IX-1596, fol. 428.

32. AHPZa, PN, leg. 602. 5-VIII-1587, fols. 534-535.

33. AHPZa, PN, leg. 360. 30-VI-1583, fols. 335-336.

34. AHPZa, PN, leg. 529. 9-XI-1587, fol. 355.

35. AHPZa, PN, leg. 482. VIII-1586, fols. 412-413; leg. 483. 3-VII-1587, fols. 384-386. 
con los animales utilizados para el transporte. Así por ejemplo, la compañía de pescado de los zamoranos Francisco Alonso y Pedro Quirós, con Juan Pérez, vecino de Tordesillas, obligaba a cada uno de ellos a poseer una «cabalgadura para el trato que valiese al menos 440 reales» ${ }^{36}$. En otras ocasiones el dato con el que contamos fue probablemente inferior al real dado que aparecen cláusulas para que en caso de no completarse todo el capital en efectivo comprometido por parte de alguno de los socios, los beneficios se repartiesen a la disolución de la compañía en función de lo aportado por cada uno ${ }^{37}$.

El capital social valorado monetariamente -como se puede apreciar en apéndice- varió enormemente de unas compañías a otras, oscilando entre los 940 y los 52.000 reales. A diferencia de lo que sucedía en otras ciudades, son raros los casos en los que las deudas de una anterior relación contractual o por un trabajo a realizar, las letras de cambio, determinadas escrituras de obligación o capital en género formasen parte del capital social de las compañías zamoranas ${ }^{38}$.

Los asociados trabajaban habitualmente a "pérdida o ganancia», aunque con diferentes porcentajes de participación y responsabilidad. Los beneficios y las pérdidas no siempre se repartieron proporcionalmente a las contribuciones de capital monetario efectuadas por ellos ${ }^{39}$. Solo en una de cada cuatro ocasiones se estableció una corresponsabilidad paritaria de beneficios y pérdidas. Por otro lado, el participar con el mismo capital no significaba necesariamente que uno se beneficiarse en la misma proporción ni que asumiese el mismo porcentaje de pérdidas ${ }^{40}$. Probablemente la disparidad en el reparto de las ganancias en algún caso respondió al volumen de trabajo o a los medios de transporte aportados por cada una de las partes. En la compañía para tratar con pescado y otras mercancías, establecida por Antonio Morales e Isabel Delgada, vecinos de Zamora, y Juan Rodríguez, vecino de Salamanca, los primeros obtendrían tres quintas partes del beneficio por encargarse de llevar las cuentas y de poner una mula, además de contratar a

36. Las bestias de carga podían servir a la compañía tan solo por su comida y si alguna se lastimaba la sociedad se lo «haría bueno» al compañero, es decir, le proporcionaría otra a su costa. AHPZa, PN, leg. 150, fols. 301-302.

37. AHPZa, PN, leg. 484-A. 28-II-1588, fols. 241-243.

38. En Barcelona solo un 30 por ciento del fondo de las compañías estuvo exclusivamente constituido por aportaciones de dinero en efectivo y en Cádiz se elevaba al 52 por ciento. LOBATO Franco, I.: Op. cit. p. 49 y Carrasco GonzÁlez, M. G.: Comerciantes y casas de negocios en Cádiz (1650-1700). Cádiz, 1997, p. 60.

39. En la compañía entre Hernán García de Losada, mercader zamorano y Pedro de Gumiel, vecino de Zamora, este último tan solo aportó su trabajo. AHPZa, PN, leg. 740. 19-VII-1599, fols. 366-367.

40. En la compañía entre Bernardo Rodríguez, vecino de Zamora y Alonso González, vecino de La Guardia, se acordó que el primero llevase dos tercios de los beneficios y tres cuartas partes de la pérdida. AHPZa, PN, leg. 397. 31-VII-1581, fol. 399. 
las personas que fuesen necesarias para la compañía ${ }^{41}$. A veces, aunque el reparto fuera proporcional, los agentes gallegos podían percibir una cantidad aparte de las ganancias. La documentación no indica en concepto de qué la recibían. Tal vez para compensar su movilidad al tener que desplazarse de un puerto a otro para conseguir el género ${ }^{42}$. De manera excepcional los emolumentos recibidos por uno de los socios estuvieron ligados a comisiones por la cantidad de género enviado, como sucedió en alguna compañía dedicada a la comercialización del pescado ${ }^{43}$.

Este reparto de beneficios entre socios también varió en función del tipo de mercancías comercializadas. Así por ejemplo, en la compañía de Bernardo López, mercader, y Antonio de Villalpando, vecinos de Zamora, este último llevaría dos séptimas partes de la ganancia o pérdida de los pescados que enviase a Bernardo a Zamora y percibiría la mitad de las ganancias de los géneros textiles que Bernardo le mandase a Pontevedra o a otras partes de Galicia para negociar con ellos ${ }^{44}$. En la de Bernardo Rodríguez y sus socios, vecinos de Zamora, con Alonso Costilla, vecino de Bayona, los primeros recibirían tres quintas partes de las pérdidas o ganancias, salvo cuando llegase el tiempo de la sabalera, incrementando su proporción a tres cuartas partes. En el caso de tratarse de cera, azúcar, palo de Brasil y otras mercaderías ultramarinas el porcentaje se fijaba en cuatro quintas partes para los socios zamoranos ${ }^{45}$.

Los contratos también se ocuparon de establecer cláusulas de cara a afrontar responsabilidades sobre las deudas contraídas o el pago de las cargas impositivas

41. AHPZa, PN, leg. 105. 31-VII-1576, fol. 332.

42. En el caso de Antonio de la Rocha, vecino de Bayona, percibiría además 300 reales, algo menos del 10 por ciento del capital monetario aportado por él. AHPZa, PN, leg. 396. 29-VII-1579, fol. 415.

43. En la compañía entre Luis de Valencia, mercader zamorano, y Rodrigo Cordero, vecino de Vigo, este último recibiría tres reales por cada carga de sardinas enviada, cuatro reales por la de raya, tres reales por la de atún, cuatro reales por la de pescado cecial y seis reales por cada carga de congrio seco o fresco. Además de la comisión podía incluso asignársele un sueldo anual. Felipa de Alba, vecina de Vigo, percibía 2 reales por carga de pescado enviada a Diego González de Silva, además de 500 reales de salario anual. Si bien Alberto Angulo subraya el auge de este sistema de comisión para el Siglo de Oro, no parece que estuviera muy extendido en la práctica mercantil zamorana. AHPZa, PN, leg. 512. 7-V-1588, fols. 53-56; leg. 519. 5-VII-1595, fol. 739. Angulo Morales, A.: «En poco tiempo vienen ricos e hazen a sus amos pobres. De factores o encomenderos a protagonistas directos del gran comercio internacional (siglos XV-XVII)» en GARCÍA FerNÁNDEZ, E. (ed.) et al.: Bilbao, Vitoria y San Sebastián: espacios para mercaderes, clérigos y gobernantes en el Medievo y la Modernidad. Bilbao, 2005, p. 84.

44. AHPZa, PN, leg. 370. 5-X-1592, fols. 514-515.

45. Los ejemplos no quedan reducidos a los citados. En la de Luis de Valencia, mercader vecino de Zamora, y Antonio de Villalpando, vecino de Bayona, el primero percibiría tres quintas partes en lo relativo al pescado y dos quintas partes cuando se tratase de cera, azúcar, becerros, paños, cobre y campanil. Si Luis le enviaba trigo castellano a Galicia el reparto de las ganancias sería igualitario. AHPZa, PN, leg. 397. 18-V-1581, fols. 193-195; leg. 402. 21-VII-1586, fols. 445-446. 
de los productos con los que se iba a negociar. Estas deudas se generaban en ocasiones por la posibilidad de que los socios vendiesen al fiado sin necesidad incluso de aportar «conocimientos» $\mathrm{u}$ «obligaciones» -escrituras notariales-. Las limitaciones se podían establecer por cliente -hasta un máximo de 110 reales por cada uno- o por volumen total de género vendido ${ }^{46}$. Existieron, no obstante, excepciones para determinados clientes. En la compañía de Blanca Bergas y Pedro Sánchez, dedicada a la comercialización de pescado, se eximió de la limitación a las mujeres de Salamanca o Peñaranda que «tratasen» en Zamora -tal vez por ser de fácil localización-, y al obligado de Madrid y mercaderes de la capital que presentasen una carta o recaudo donde se reflejase la petición del género, la cual probablemente actuaría como documento probatorio en caso de conflicto ${ }^{47}$.

En algunos casos el cobro de las deudas generadas a favor de la compañía por los agentes residentes o estantes en Galicia corría a costa de estos últimos y el de las mercancías vendidas en Castilla quedaba a cargo del socio o socios zamoranos, independientemente de si se considerasen «buenas», es decir, factibles de cobrar, o no ${ }^{48}$. Algunos contratos establecieron que ninguno de los socios diese cuenta al otro de estas deudas salvo las que pareciesen que iban «a ser pérdida». En tales circunstancias, cada uno afrontaría su responsabilidad ${ }^{49}$. Generalmente las pérdidas o deudas de carácter dudoso corrían a costa de la compañía siendo afrontadas en proporción al capital monetario invertido por cada uno de los socios «por solo su asiento del libro, ora sea por escritura o sin ella» ${ }^{50}$. Como ha subrayado Michel Balard lo escrito en los libros de los mercaderes debía ser suficiente incluso para los negocios más simples y la confianza constituía la base en las relaciones de negocios ${ }^{51}$.

46. En la compañía entre Antonio Vergas, vecino de Zamora, y Antonio de la Peña, vecino de Peñaranda, se estipuló en 800 reales, cuantía que no superaba el 4\% del capital monetario aportado por los socios y que no afectaba gravemente a la viabilidad de la sociedad. AHPZa, PN, leg. 495. 1-VIII-1581, fols. 258-260.

47. AHPZa, PN, leg. 484. 28-II-1588, fols. 241-243.

48. En ocasiones el socio gallego también lo realizaba con las de Portugal. Si bien cada uno se responsabiliza de hacer efectivo ese capital y pagarlo de su peculio en caso de salir dudosas las deudas, existieron excepciones al respecto. Así por ejemplo, Bernardo López, mercader zamorano, se comprometió a abonar la mitad de las que su socio Antonio de Villalpando generase en Galicia. En otros casos el socio de Zamora se responsabilizaba de las del otro y viceversa, «heredándolas» a la disolución de la compañía; otras veces se cubrían en proporción a lo aportado por cada uno o las quiebras en Castilla las asumía la sociedad. También encontramos situaciones en las que al socio estante en Galicia o Portugal se le prohibía generar deudas de ningún tipo. AHPZa, PN, leg. 370. 5-X-1592, fols. 514-515; leg. 401. 23-VII-1585, fols. 578-579; leg. 520. 2-VI-1596, fols. 408-409; leg. 521. 22-VII-1597, fol. 1163; leg. 681. 4-VII-1599, fol. 526; AHPZa, PN, leg. 709. 14-VIII-1596, fols. 338-339; leg. 740. 19-VII-1599, fols. 366-367; leg. 741. 9.VIII-1600, fols. 701-702.

49. AHPZa, PN, leg. 402. 29-VII-1586, fols. 451-452.

50. AHPZa, PN, leg. 609. 12-VII-1593, fols. 404-405.

51. BALARD, M.: «La culture du marchand occidental en Méditerranée orientale», en AurELL, J. (ed.): El mediterráneo medieval y renacentista, espacio de mercados y de culturas. Pamplona, 2002, p. 42. 
En cuanto a las letras libradas por el socio gallego, el zamorano estaba obligado a «cumplirlas y pagarlas como en ellas se contuviere» siempre y cuando su cuantía no excediese el capital en efectivo que hubiera aportado a la sociedad el socio que las emitía. En algunos casos se exigía un aviso previo con un determinado tiempo de antelación ${ }^{52}$. El deterioro y los hurtos ocasionados en el traslado de la mercancía de un puerto a otro así como el pago de tributos -alcabala, sisa, peso, etc.- eran afrontados por el fondo de la compañía ${ }^{53}$. No obstante, hallamos excepciones como la de Antonio Morales Varejón, mercader zamorano, y Francisco Martínez, vecino de La Guardia, quienes acordaron pagar cada uno lo que le correspondiese del peso y alcabala y que Francisco percibiese 100 reales aparte de las ganancias para ayudarle a afrontar estos impuestos ${ }^{54}$.

Los aspectos relativos a la gestión de las compañías son los que más lagunas presentan al no haberse conservado ninguno de sus libros ${ }^{55}$. Los documentos fundacionales también omiten este aspecto en cuatro de cada diez casos y no se observa una especialización ni la diversidad profesional de otras ciudades -directores, cajeros, consejeros o supervisores-. Sí se aprecia -como sucedería para Barcelona en el siglo XVII y principios del siglo XVIII- un predominio de la administración única -en el 71 por ciento de los casos indicados-, frente a la compartida -29 por ciento de los casos ${ }^{56}$. Los documentos contables fueron en su mayoría gestionados personalmente por los mercaderes. Un 86,4 por ciento de ellos firmaron las escrituras fundacionales -esta cifra se reduce a un 8 por ciento en el caso de las mujeres- claro indicio de su elevada alfabetización y capacidad para anotar las partidas contables ${ }^{57}$.

En las sociedades dedicadas al pescado, el socio zamorano, quien más capital monetario solía exponer, era quien habitualmente fiscalizaba las cuentas actuando

52. En la compañía entre Antonio de Villacorta, el Mozo, Francisco Alonso Lagartero y Alonso González de Silva, mercaderes zamoranos, se estableció el período de aviso en ocho días. AHPZa, PN, leg. 400. 8-VII-1584, fols. 327-328; leg. 739. 7-XI-1598, fols. 728-729.

53. AHPZa, PN, leg. 396. 31-III-1579, fol. 215; leg. 396. 29-VII-1579, fol. 412; leg. 518. 6-VII1594, fols. 336-337; leg. 402. 29-VII-1586, fols. 451-452; leg. 524. 15-VI-1600, fols. 425-426; leg. 639. 9-VI-1592, fol. 278.

54. AHPZa, PN, leg. 400. 8-VII-1584, fols. 333-334.

55. La escasez de este tipo de fuentes contables ha sido constatada igualmente en otros estudios del interior peninsular. Ver MONTEMAYOR, J.: Toléde entre fortune et déclin (1530-1640). Limoges, 1996, p. 235.

56. Lobato Franco, I.: «Modelos y métodos de gestión en la compañía mercantil preindustrial (Barcelona, 1650-1729)», Cuadernos de Estudios Empresariales, 6 (1996), p. 232.

57. Ignoramos a qué tipo de individuos recurrieron aquellos que no sabían escribir, como Juan Cedrón, vecino de Zamora, y Luis Hernández, vecino de Arcenillas, que fundaron una compañía para tratar con vino y mosto. Ambos debían asentar lo que gastaban "para echar cuenta y razón» pero ninguno de ellos llegó a firmar el documento fundacional de la compañía. AHPZa, PN, leg. 477. 12-X-1599, fols. 85-92. 
como «caxa» $\mathrm{y}$ «rezibo» en dos de cada tres casos. Conservaba un libro de razón o «de caja y cuenta», también denominado de cargo y descargo -en ocasiones acompañado de un borrador- donde constaban todas las ventas, compras, dineros enviados, portes, portazgos, impuestos, incluso puertos de salida del género, nombre de los compradores, lugares de residencia de estos y precios de los productos ${ }^{58}$. En menor medida el compañero gallego solía también contar con un «libro de marca mayor» donde se reflejaba el género comprado y vendido, así como el dinero enviado a la ciudad de Zamora, el cual podía remitirse a través de arrieros. Independientemente de si la contabilidad se realizaba por uno de los socios o por ambos, quien la efectuaba debía ser creído por tal «libro de cuenta y razón» sin necesidad de proceder a ninguna otra diligencia ${ }^{59}$. A pesar de este margen de confianza se exigía igualmente que tuvieran dichos libros «buenos y ciertos ${ }^{60}$. Excepcionalmente quien gestionaba las cuentas percibía una cantidad determinada que se detraía de las ganancias ${ }^{61}$. Al margen de los aspectos contables, en ningún contrato hemos constatado que se estableciesen marcas que deberían llevar los productos de estas sociedades comerciales a diferencia de lo que sucedió en Salamanca con algunos libreros o en el norte de Europa ${ }^{62}$.

\section{El objeto social de las compañías}

Las actividades comerciales de las compañías zamoranas estuvieron orientadas fundamentalmente a la importación de pescado desde Galicia o desde Portugal ${ }^{63}$. Tres de cada diez trabajaron con este producto de manera exclusiva y otras cuatro

58. AHPZa, PN, leg. 397. 18-IV-1581, fols. 193-195; leg. 521. 6-VI-1597, fol. 693; leg. 739. 7-XI-1598, fols. 728-729.

59. En la sociedad de Fernando Mesego, vecino de Bayona, y Diego González de Silva, mercader zamorano, se especificaba que «por las cartas y libros de anbos se ha de estar y dar crédito según que es costumbre entre mercaderes». AHPZa, PN, leg. 566. 6-VII-1587, fols. 237-238.

60. AHPZa, PN, leg. 301. 7-V-1578, fol. 301.

61. Francisco Alonso Lagartero percibiría 20 ducados de sus compañías y Hernán García de Losada 900 reales del suyo. AHPZa, PN, leg. 740. 2-VII-1599, fols. 341-342; leg. 740. 19-VII-1599, fols. 366-367; leg. 741. 5-VII-1600, fols. 641-642.

62. Jeanin, P.: Marchands du Nord: espaces et trafics à l'époque moderne. (Textes réunis par Philippe Braunstein et Jochen Hoock). París, 1996, pp. 91 y 94.

63. E. E. Rich y C. H. Wilson indican la importancia de Galicia en el suministro de pescado consumido en Castilla, hecho que fue subrayado también en la época por las Cortes. Esta dedicación a comerciar con pescado gallego ocupó igualmente un lugar preponderante en los negocios de la burguesía maragata, como lo manifiestan los inventarios de sus profesionales, y entre los mercaderes vallisoletanos, especialmente los de Medina de Rioseco. Rich, E. E. y Wilson, C. H.: Historia económica de Europa. Tomo V. La organización económica en Europa en la Edad Moderna. Madrid, 1981, p. 226; RuBIo PéreZ, L. M.: La burguesía maragata. Dimensión social, comercio y capital en la corona de Castilla durante la Edad Moderna. León, 1995, p. 232; Yun Casalilla, B.: Sobre la transición al capitalismo en Castilla. Economía y sociedad en Tierra de Campos (1500-1800). Valladolid, 1987, p. 198. 
de cada diez lo combinaron con «otras mercadurías» ${ }^{64}$. Entre ellas se cita azúcar, cera, especias, palo de Brasil, «campanil»-metal para fabricar campanas-, cobre, vino, trigo, paños y ganado, aunque no siempre se concretaron en la documentación los géneros que se iban a negociar junto al pescado ${ }^{65}$. El resto trataron, además de con las mercancías anteriormente citadas, con seda, cueros, gualda, cardón, lanas y «añinos». No obstante, estas sociedades destinadas al tráfico de productos perecederos podían quedar eventualmente abiertas a otros tipos de negocios como el arrendamiento de alguna renta municipal ${ }^{66}$. Parte de los documentos no explicitan el tipo de actividades a las que se aplicaría el capital en efectivo dejado por el «socio capitalista» a los otros. Les facultaba para que efectuasen «todos los tratos lícitos que quisieren y por bien tuvieren ${ }^{67}$. En estos últimos casos nos encontraríamos, en opinión de Hilario Casado, ante sociedades mercantiles con escaso desarrollo institucional y de comportamiento flexible, ya que sus objetivos eran variados y adaptables a cualesquier circunstancias económicas ${ }^{68}$.

Si atendemos a las relacionadas con el pescado, el de Galicia solía traerse de los puertos de Pontevedra, Bayona, La Guardia, Ría de Arosa y Villamayor ${ }^{69}$; y el de la zona cantábrica de Vizcaya. Aquí se compraban escabeches a través de agentes

64. La fundación de pequeñas compañías para la comercialización del pescado fue también habitual en las zonas portuarias y los comerciantes dedicados a este producto también tuvieron un papel relevante en las del interior -en Vitoria 19 de 89 mercaderes de una relación del año 1578-aunque no llegaron al nivel porcentual de las compañías zamoranas Ver AzPiAzU, J. A.: Sociedad y vida social vasca en el siglo XVI. Mercaderes guipuzcoanos. Tomo I. Oirarzun, 1990, p. 328 y Angulo Morales, A.: «Grandes negocios y tramas mercantiles a fines del reinado de Felipe II». En Martínez Millán, J. (dir.): Felipe II (1527-1598). Europa y la Monarquía Católica. Tomo II, 1998, p. 88; BilbaO, L. M.: «Entre Castilla y Francia: comercio y comerciantes en Bilbao a mediados del siglo XVI», Revista de Historia Económica, 27 (2009), pp. 120-121.

65. Aparecen referencias del estilo: «...y otras mercadurías tocantes que más convengan a la dicha compañía»; «...y otras cualesquier mercadurías»; « ...y otras cualesquier mercadurías de sobremar». AHPZa, PN, leg. 105. 31-VII-1576, fol. 332; leg. 439. 31-XII-1579, fols. 1137-1138; leg. 397. 18-IV1591, fols. 193-195.

66. Así se explicita en las cláusulas contractuales de la compañía entre Juan de Astorga, mercader zamorano, y Antonio de Villalpando, vecino de Bayona, creada para el trato de pescado, cera, azúcar, escabeche y otras mercancías de ultramar. En el caso de que el segundo de los socios citados deseara «tomar rentas» de la villa de Bayona hasta en cuantía de 2.000 ducados (22.000 reales) lo haría para la dicha compañía. AHPZa, PN, leg. 399. 16-VI-1583, fols. 303-304.

67. AHPZa, PN, leg. 476. 3-VIII-1598, fols. 767-768.

68. Casado Alonso, H.: «Comercio, crédito y finanzas públicas en Castilla en la época de los Reyes Católicos», en Bernal Rodríguez, A. M. (coord.): Dinero, Moneda y Crédito en la monarquía hispánica. Madrid, 2000, p. 141.

69. De la zona de la Ría de Arosa se citan factores procedentes de localidades como Villajuán y O Carril. Se indica en algún documento que se traería de los puertos de la «sabalera» pero ignoramos si se refiere a una localidad denominada de este modo o a un lugar donde se realizaban operaciones de venta de sábalos. AHPZa, PN, leg. 396. 31-III-1579, fol. 215; leg. 478. 5-X-1580, fol. 538; leg. 360. 14-VI-1583, fols. 365-366. 
residentes en Castro Urdiales ${ }^{70}$. Los documentos aluden a diferentes variedades de pescado como sardinas -frescas y «de humo»-, congrio -verde y en ocasiones cecial o seco, procedente de los puertos de Cangas y de Vigo ${ }^{71}$ - raya, «bacallón» ${ }^{72}$ y sábalos ${ }^{73}$. Algunos agentes gallegos estaban obligados, así mismo, a «asistir a la sabalera» y enviar el sábalo a Zamora, a Benavente o a Medina de Rioseco ${ }^{74}$. El congrio se compraba en «empeño», es decir, de un año a otro ${ }^{75}$. También se hacen menciones genéricas a especies en función de las artes de pesca utilizadas, caso de «pescado de cordel $»^{76} \mathrm{y}$ «volante» ${ }^{77}$; o se alude, tras efectuar una relación de algunos tipos de peces, a «todo género de pescados» ${ }^{78}$. Ignoramos si los que se citaban de una manera específica eran los más demandados. Sobre este aspecto solamente contamos con la información proporcionada por las cuentas correspondientes a seis meses -de finales de octubre de 1587 a marzo de 1588 (ver cuadro 2)- de la compañía de Diego González de Silva las cuales arrojan el resultado siguiente:

70. Igualmente agentes de la zona de la Ría de Arosa, concretamente de la villa de O Carril, estaban obligados a enviar escabeches a Zamora. AHPZa, PN, leg. 360. 19-VI-1583, fols. 363-364; leg. 361. 4-V-1584, fol. 205.

71. Gregorio Fontefría se comprometió a conseguir entre 50 y 60 cargas de congrio cecial a Pedro de Quirós, mercader de pescados zamorano. AHPZa, PN, leg. 439. 7-V-1578, fol. 301.

72. El «bacallón» también procedía de Portugal. Antonio Vergas firmó un contrato con Marcos de Medina, ambos mercaderes zamoranos, para importar 320 arrobas portuguesas de este tipo de pescado. Igualmente Diego Vergas se concertó con Diego Enríquez, mercader portugués, procedente de Miranda, para que le trajera 360 arrobas de «bacallón». AHPZa, PN, leg. 402. 21-VII-1586, fols. 445-446; leg. 521. 22-VII-1597; leg. 528. 1-III-1586, fols. 51-52; leg. 529. 9-XI-1587, fol. 357.

73. En el contrato del mercader zamorano Antonio de Vergas con Juan Gómez, vecino de Torboes, de la jurisdicción de Pinel (Portugal), este último se encargó de traer los «sábalos de los ríos de Galicia a real cada pez, así fresco como salado». A través de algunas cartas de obligación y de la documentación municipal se constata que también se vendían en Zamora sollos, besugos, toninas o atunes, lenguados, salmón y lampreas. AHPZa, PN, leg. 529. 9-XI-1587, fol. 355; leg. 523. 13-IV-1599, fols. 198 y 203. Ferrero Ferrero, F. y Martín MÁrQuez, A.: Del comer, beber y arder. Historia de los abastos en Zamora. Zamora, 2006, p. 83.

74. No solo se limitaba al sábalo sino que podía extenderse a otros géneros de pescado. En alguna de ellas el socio zamorano no podría asistir a la sabalera o hacerla por otra persona. AHPZa, PN, leg. 356. 26-VI-1578, fols. 498-499; leg. 400. 8-VII-1584, fols. 327-328; leg. 740, fols. 341-342; leg. 741. 5-VII-1600, fols. 641-642.

75. AHPZa, PN, leg. 521. 22-VII-1597, fol. 1163.

76. AHPZa, PN, leg. 396. 31-III-1579, fol. 215.

77. AHPZa, PN, leg. 396. 29-I-1579, fol. 412. y 29-VII-1579, fol. 415; leg. 495. 15-VII-1581.

78. Según el historiador zamorano Cesáreo Fernández Duro, sería en el año 1537 cuando «se señalaron los pesos de pescado fresco y salado» en la urbe. La ciudad contó desde la Edad Media con ordenanzas similares a las de las ciudades castellanas en las que se regulaban los derechos del arrendador del pescado, los lugares de venta, los posibles vendedores y la permanencia del género en la ciudad, entre otros aspectos. Ver FernándeZ Duro, C.: Memorias históricas de la ciudad de Zamora, su provincia y obispado. T. III. Madrid, 1882, p. 266 y Del Canto de la Fuente, C.; Carbajo MarTín, V. A. y Moreta Velayos, S.: Ordenanzas municipales de Zamora. Siglos XV y XVI. Zamora, 1991, pp. 95-100. 
Cuadro 2. Compra de pescado de la compañía de Diego González de Silva (octubre 1587-marzo 1588)

\begin{tabular}{|l|c|c|}
\hline \multicolumn{1}{|c|}{ Producto } & Cargas & Precio de la carga (reales) \\
\hline Sardina fresca & 116 & $54-93^{79}$ \\
\hline Congrio & 8 & 102 \\
\hline Atún & 2 & 44 \\
\hline Raya & 2 & 126,5 \\
\hline Pulpo & 7 & 15 \\
\hline
\end{tabular}

Como se puede apreciar, en esta compañía la sardina fue el producto estrella a larga distancia con respecto al segundo de los pescados, el congrio ${ }^{80}$; sin embargo, a través de las cartas de obligación de otros años, como el de 1599, se observa que el congrio copaba el primer lugar de los géneros mandados a Segovia o a Madrid desde Zamora ${ }^{81}$. De todas las formas no hemos de extraer conclusiones precipitadas ya que estamos ante los datos de una única compañía y falta el asiento de varios meses en los cuales pudo variar la demanda respecto a uno u otro tipo de pescado ${ }^{82}$.

En lo que respecta a las condiciones en las que se realizaban estas transacciones comerciales, en algunos documentos se señala que el socio ubicado en Galicia no "cargaría ningún maravedí» salvo el gasto de esteras ${ }^{83}$, «cuerda y liar», sal, alcabala y costo del camino. También percibiría una dieta cuando saliese de la villa en la cual residía para adquirir géneros en otros lugares ya que contractualmente se encontraba obligado a buscar la mercancía en el puerto en el que la hubiere. Igualmente se compensaba al socio zamorano si tenía que ausentarse de la ciudad a vender el producto a otras zonas. En ocasiones se obligaba a que la venta se efectuarse «de contado y no fiado» ${ }^{84}$. El socio gallego también debía informar del género existente

79. El precio se incrementaba en un ducado si las cargas estaban «hechas», frente a las «deshechas». Con esta expresión tal vez se haga alusión a si venían compuestas o aderezadas, o no.

80. La sardina tuvo un papel relevante en Valencia representando el 50 por ciento del pescado introducido por buques ingleses y bretones que fueron desplazando a la de origen gallego y en menor medida a la andaluza y portuguesa. FRANCH BENAVENT, R.: «El proceso de concentración de los negocios y las actividades marítimas en la España Moderna», en DuberT, I. y SObrado Correa, H. (Eds.): El mar en los siglos modernos. Tomo I. Santiago de Compostela. 2009, p. 194.

81. AHPZa, PN, leg. 523. 13-IV-1599, fols. 198-204.

82. AHPZa, PN, leg. 512. 7-V-1588, fols. 53-56.

83. La documentación indica que el pescado solía también cargarse en cajas y cañizos. La tara de la estera se estableció en algunos documentos en 8 libras. AHPZa, PN, leg. 397. 18-IV-1581, fols. 193-195; leg. 529. 9-XI-1587, fol. 357.

84. AHPZa, PN, leg. 397. 31-VII-1581, fol. 399; leg. 400. 8-VII-1584, fols. 333-334. 
para saber qué deseaba su compañero, lo cual se lograba a través del intercambio de correspondencia entre los asociados ${ }^{85}$. De hecho, en algún contrato se obligaba a que solo comprase las mercancías «avisadas» por el compañero ${ }^{86}$. El socio de Galicia no podría vender pescado en el lugar donde residía ni en otras partes durante el tiempo que durase la compañía, excepcionalmente lo haría por orden del compañero zamorano repartiendo los beneficios con el resto de los socios de la compañía. Tampoco podía «hacer carga alguna para otra persona», es decir, enviar género a quien no fuese de su sociedad ${ }^{87}$. Excepcionalmente hallamos factores que sirvieron a dos sociedades conjuntamente, caso de Gregorio de Fontefría, vecino de Vigo, que trabajó en el mismo año, el de 1578, para Antonio de Quirós y Ana de Rivera. En la formada por Luis de Valencia, mercader zamorano, y Alonso de Costillas, mercader, vecino de Bayona, se le concedía a este último la posibilidad además de que cargara mercaderías o sardinas para Canarias hasta una cantidad de 200 ducados -2.200 reales- pero a costa de todos los socios ${ }^{88}$. En la que tenía el primero con Rodrigo Cordero, vecino de Vigo, se estipuló que si este último adquiría pescados para otra persona debía compensar a Luis con dos reales por carga ${ }^{89}$. Igualmente, los vendedores zamoranos estaban obligados a dar salida prioritariamente al género de la compañía antes de comprarlo a otras personas; en caso contrario se responsabilizaban de las pérdidas ${ }^{90}$.

Cuando se trataba de envíos de dinero entre los socios, efectuados a través del arriero, en el supuesto de que este se ausentase se le daría credibilidad al emisor simplemente mostrando el libro de caja en el cual debería figurar la partida, a través de quién la había enviado, de dónde era vecino el recuero, y el día, mes y año de la operación ${ }^{91}$. La pérdida correría a cargo de todos los socios en función

85. De hecho las cuentas se realizaban en ocasiones «por los libros e cartas mesibas que hobiere». AHPZa, PN, leg. 401. 23-VII-1585, fols. 578-579; leg. 521. 6-VI-1597. leg. 739. 9-IV-1598, fols. 202-203; leg. 740. 19-VII-1599, fols. 366-367; leg. 741. 25-V-1600, fols. 605-606.

86. AHPZa, PN, leg. 516, fols. 582-584; leg. 524. 29-VII-1600, fol. 533.

87. Sin embargo, sí podemos encontrar mercaderes zamoranos surtiéndose de personas diferentes. Luis de Valencia tenía como proveedores a Alonso Pérez, de La Guardia; a Rodrigo Cordero, de Vigo, y a Hernando Acayna de Pontevedra. A diferencia de lo que sucedía en Zamora, en el caso inglés sí existía la posibilidad de que un factor trabajase para varios patronos conjuntamente. AHPZa, PN, leg. 523. 1-X-1599. Testamento de Luis de Valencia y Beatriz Álvarez. LANERo FernÁndeZ, J. J.: «De aprendiz a mercader. El factor en el comercio internacional inglés en el siglo XVI», Pecunia. Revista de la Facultad de Ciencias Económicas y empresariales, 5 (2007), p. 174.

88. AHPZa, PN, leg. 401. 23-VII-1585, fols. 578-579.

89. AHPZa, PN, leg. 519. 5-VII-1595, fol. 739.

90. AHPZa, PN, leg. 439. 31-XII-1579, fols. 1137-1138.

91. Francisco Alonso Lagartero, mercader zamorano, y Martín Gómez, mercader, vecino de Bayona, ante tal eventualidad establecieron que la pérdida fuese asumida por ambas partes proporcionando Martín «claridad y verdad del asiento y cómo se llama el tal arriero e persona y dónde es veçino y la cantidad que llebaba» en AHPZa, PN, leg. 740. 2-VII-1599, fols. 341-342. 
a su porcentaje de participación ${ }^{92}$. Solo de manera excepcional el riesgo lo asumía quien mandaba el peculio ${ }^{93}$.

La documentación nos permite apreciar cómo varios mercaderes dedicados a la comercialización del pescado estuvieron embarcados en más de una compañía simultáneamente. Antonio Morales Varejón, Juan de Astorga, Antonio de Vergas, Bartolomé de Villalpando, Luis de Valencia o Bernardo López establecieron en un mismo año sociedades con diferentes individuos para negociar fundamentalmente con pescado. Otros diversificaron sus negocios a través de diferentes compañías, caso de Pedro Sánchez, quien se encargaba de las compras de ganado para la carnicería de la ciudad con otros socios y a su vez gestionaba otra sociedad con Blanca Bergas. Esta última se dedicaba a negociar con pescados y azúcar adquiridos en Galicia, Portugal y Vizcaya para luego venderlos en Madrid, Salamanca ${ }^{94}$ y Peñaranda de Bracamonte ${ }^{95}$. Dado el volumen de trabajo que mantenía se le obligó a que no pudiese ausentarse de la ciudad «a negocio propio o ajeno».

$\mathrm{Al}$ margen de estas compañías dedicadas al pescado, en el ámbito agropecuario encontramos algunas fundadas para comercializar con vino tinto y mosto que solían dispensarse en tabernas que alguno de los socios había tomado a renta ${ }^{96}$. Diego García y Antonio de Medina, mercaderes de Zamora, establecieron una sociedad con Francisco Prieto, vecino de Villamor de los Escuderos, para vender todo el vino que este último y una tal Ana Hernández tuviesen almacenado en la dicha villa y en la bodega del Colegio de Pan y Carbón de Salamanca. Debían darle salida en el momento en que el producto adquiriese su precio más elevado en el mercado. Los dos primeros habían arrendado a la citada institución universitaria el lagar y bodega que dejarían a disposición del segundo. El volumen del negocio se limitaba a cuatro cubas de vino que hacían unos 700 cántaros -casi 11.300 litros-. Los posibles beneficios se repartirían el día de San Miguel a razón

92. AHPZa, PN, leg. 397. 18-IV-1581, fols. 193-195; leg. 400. 8-VII-1584, fols. 333-334.

93. Así sucedió con la compañía de Luis de Valencia, mercader zamorano, y Rodrigo Cordero, vecino de Vigo. AHPZa, PN, leg. 515. 1-VI-1591, fol. 391.

94. La venta podía ser a otros mercaderes o a través de un dependiente del mercader zamorano. Antonio González de Tapia, vecino de Zamora, obligado del pescado en Salamanca, se concertó con Francisco de Tapia -ignoramos si era familiar suyo- para que comerciase en la ciudad del Tormes con los pescados enviados desde Zamora. Si salía fuera de Salamanca a venderlos le proporcionaría una cabalgadura y le abonaría la posada y la comida. Tendría un libro de asiento de compras, ventas y recibos donde anotase las operaciones. Recibiría un salario anual de 450 reales y se le permitía vender jabón y aceite. De estos últimos productos se beneficiaría con la mitad de las ganancias. En el caso de enfermar podía desplazarse a la ciudad de Zamora para curarse. AHPZa, PN, leg. 723. 23-XI-1598, fols. 506-507.

95. AHPZa, PN, leg. 484A. 28-II-1588, fols. 241-243.

96. El alquiler del local donde se expendía podía correr a costa de la compañía. Ver. AHPZa, PN, leg. 696. 13-XI-1600, fol. 498. 
de un tercio por cada uno de los socios ${ }^{97}$. En la establecida por Francisco Díez, Jerónimo de Vargas y Antonio Sánchez, vecinos de Zamora, el tinto objeto de comercialización, comprado por los meses de enero y febrero, alcanzaría hasta los 2.000 cántaros $^{98}$. Este producto se conseguía en núcleos rurales cercanos a la ciudad de Zamora como Arcenillas o Casaseca de las Chanas ${ }^{99}$. Compraban directamente a los agricultores y alquilaban cubas en los lugares donde se cosechaba para su elaboración.

En el caso de las destinadas a «tratar» con ganado, solían hacerlo habitualmente con ovejas, cabras, carneros y corderos ${ }^{100}$. Las compañías orientadas al abasto de las carnicerías así mismo se dedicaban a la adquisición de las reses. En este tipo de sociedades solía haber una notable presencia de personas procedentes de la villa de Carbajales. El socio destinado a la gestión podía estar excluido de la labor de tratante o al menos de desplazarse fuera de la ciudad de Zamora para conseguir el género circunscribiéndose sus funciones a la organización del establecimiento, a las cuentas con el matadero, a «tomar razón» a los «cortadores y pastores», a controlar la carne que se entregaba semanalmente y a cobrar las deudas ${ }^{101}$. Este trabajo administrativo le podía reportar un estipendio añadido al de las ganancias de la compañía ${ }^{102}$. Quien actuaba como «caja» tenía la obligación de pagar las letras que le enviasen sus compañeros y de mandarles dinero a las ferias. Los animales -vacas, bueyes, ovejas y castrones- solían comprarse, entre otros lugares, en Galicia y en el «Extremo» (Extremadura) ${ }^{103}$. Las obligaciones generadas por los cueros, pellejos, carne, sebo y asaduras corrían a costa de la compañía. Al socio dedicado a las compras se le podía proporcionar una cabalgadura para portar el dinero ${ }^{104}$.

Más atípicas por su excepcionalidad fueron las sociedades para la comercialización de hierro, como la de Francisco Rodríguez Montesino, vecino de Zamora, y Antonio Maniego, vecino de Morales; o de plantas tintóreas como la gualda -empleada para conseguir tinte amarillo- y el cardón -del cual no se

97. AHPZa, PN, leg. 398. 10-XII-1582, fol. 639.

98. AHPZa, PN, leg. 695. 26-XII-1599, fols. 661-662.

99. AHPZa, PN, leg. 477. 12-X-1599.

100. Alonso Osorio, vecino de Zamora, y Catalina de Valladolid y Marcos de Medina, su hijo, realizaron una compañía con 642 ovejas de vientre, 433 carneros, 384 corderos y 248 cabezas de ganado caprino. Obtuvieron de su esquileo 12.574 reales que repartieron entre ambos de manera igualitaria. AHPZa, PN, leg. 156. 8-VIII-1581, fol. 226; leg. 610. 28-IV-1594, fols. 307-308.

101. AHPZa, PN, leg. 360. 30-VI-1583, fols. 268-269; leg. 482. VIII-1586, fols. 412-413; leg. 485A. 26-VII-1589, fols. 787-789.

102. Pedro Sánchez percibió por su labor de gestión salarios que oscilaron entre 300 y 500 reales, además de su porcentaje de ganancias. AHPZa, PN, leg. 482. VIII-1586, fols. 412-413; leg. 483. 3-VII-1587, fols. 384-386; leg. 485A. 26-VII-1589, fols. 787-789.

103. AHPZa, PN, leg. 602. 20-II-1587, fols. 135-136.

104. AHPZa, PN, leg. 483, fols. 384-386. 
indica su posible utilidad-105. Este último adquiría el cardón en Toro y la gualda en Morales, aunque parte de ella procedía de Portugal, y se vendía en Ávila y Segovia ${ }^{106}$. A diferencia de las compañías hasta aquí tratadas, el socio «capitalista» podría demandar al «encomendado» cuenta «con pago del dinero» cuando lo desease. Lo mismo sucede con las dedicadas a la compraventa de paños, lienzos o seda, representadas tan solo por cuatro compañías. Este dato contrasta con lo sucedido en otras zonas y con la incipiente actividad que tuvo el gremio textil en la ciudad durante esta centuria ${ }^{107}$.

\section{LA DISOLUCIÓN DE LAS COMPAÑÍAS}

Una de las características más sobresalientes de las compañías zamoranas radica en su breve duración ${ }^{108}$. Aunque su tiempo operativo osciló entre un mes y los tres años, prácticamente nueve de cada diez formalizaron sus contratos para trabajar durante un año o menos -ver cuadro 3-109. Las más efímeras estuvieron dedicadas a transacciones de productos agrícolas -aceite, vino, etc.-, limitándose probablemente a comercializar en las épocas cercanas a las cosechas; así como las que trabajaron con productos textiles. La establecida por el licenciado Antonio de Tapias Vargas, estante en Zamora, y Antonio Hernández, lencero, para comercializar con lienzos, duraría hasta la venta del "primer empleo», es decir, hasta dar salida al género adquirido. La posible continuidad de la sociedad quedaría a la elección de ambos compañeros ${ }^{110}$.

105. AHPZa, PN, leg. 539. 17-IX-1597, fols. 290-291.

106. AHPZa, PN, leg. 540. 31-III-1598, fols. 184-185.

107. Frente a su escasa presencia en Zamora, en Barcelona las de tejidos supusieron el 47,02 por ciento de las compañías y el 73,89 por ciento de los capitales aportados; en Medina del campo el 45,8 por ciento y en Zaragoza y La Rioja la mayor parte de los mercaderes y sociedades estuvieron orientados a productos textiles «al por menor». AHPZa, PN, leg. 611. 9-XI-1595, fol. 674; ABED Al-Hussein, F. H.: Art. cit., p. 205; Gómez Zorraquino, J. I.: Op. cit., p. 118; Lobato Franco, I.: Op. cit. p. 109; Goicolea Julián, F. J.: «Mercaderes y hombres de negocio: el poder del dinero en el mundo urbano riojano de fines de la Edad Media e inicios de la Edad Moderna», Hispania. 227 (2007), pp. 947-992 y Diago HernANDO, M.: «Mercaderes y hombres de negocios en La Rioja a finales de la Edad Media». Brocar 31 (2007), pp. 369-409.

108. Para Bartolomé Yun Casalilla esta corta vida de las compañías «constituye una garantía de movilidad y versatilidad, según los vaivenes del comercio especulativo». Yun CasaliLla, B.: Op. cit. p. 200.

109. En Barcelona solo 12 de 126 compañías operaron durante un año o menos. Franco LOBATO, I.: Op. cit., p. 89.

110. AHPZa, PN, leg. 658. 30-III-1599, fol. 272. 
Cuadro 3. Duración de las compañías zamoranas en el siglo Xvi (1575-1600)

\begin{tabular}{|l|c|}
\hline \multicolumn{1}{|c|}{ Tiempo } & Número de compañías \\
\hline Menos de un año & 17 \\
\hline 1 año & 60 \\
\hline 2 años & 1 \\
\hline 3 años & 1 \\
\hline Sin Determinar & 6 \\
\hline Total de compañías & 85 \\
\hline
\end{tabular}

Una vez concluían las operaciones comerciales, los socios solían citarse en Zamora para hacer cuentas y finiquitar la sociedad ${ }^{111}$. Excepcionalmente, hallamos compañías en las que los miembros las podían realizar de manera periódica, bien mensual o trimestralmente. No fueron, precisamente, aquellas que aportaron un mayor capital monetario y requiriesen, por tanto, un control más exhaustivo las que adoptaron este tipo de fiscalización ${ }^{112}$. Habitualmente se otorgaban plazos de entre cuatro días y un mes para proceder a la liquidación de cuentas efectuadas a través de los libros de asiento. En caso de existir alguna duda se ofrecía un margen de confianza a los socios bajo formulismos del estilo: «serían creídos cada uno por su juramento sin otra averiguación» ${ }^{113}$. Dado que el género con el que trabajaban en la mayoría de los casos era de carácter perecedero podía exigirse al socio vendedor que hubiera dado salida a toda la mercancía antes de proceder a la disolución de la sociedad ${ }^{114}$. Saldadas las cuentas, los «alcances» o deudas entre los asociados deberían teóricamente abonarse al contado, o como se indicaba en los documentos: «cuenta con pago», aunque no siempre se procedió de esta manera ${ }^{115}$. La devolución del dinero por parte del socio «alcanzado» podía quedar

111. Fue habitual en otras zonas que el rendimiento de las cuentas se hiciese en el lugar donde se había efectuado la administración ya que allí se contaba con la mayoría de los instrumentos de gestión y prueba. Ver. PETIT, C.: La compañia mercantil bajo el régimen de las ordenanzas del Consulado de Bilbao. 1737-1829. Sevilla, 1980, p. 198.

112. AHPZa, PN, leg. 740. 6-X-1599; leg. 741. 28-VII-1600, fols. 672-673.

113. AHPZa, PN, leg. 739. 9-VI-1598, fols. 202-203.

114. En el contrato entre Pedro Quirós, mercader de pescados, vecino de Zamora, y Gregorio Fontefría, vecino de Vigo, se estableció que tuviese vendido todo el pescado cecial para Pascua del Espíritu Santo. AHPZa, PN, leg. 439. 7-V-1578, fol. 301.

115. En la compañía entre Bernardo Rodríguez, vecino de Zamora, y Alonso González, vecino de La Guardia; o en la de Antonio Morales Varejón, mercader zamorano y Francisco Martínez, vecino de La Guardia, se otorgó un plazo de cuatro días tras fenecer las cuentas para abonar las deudas. AHPZa, PN, leg. 397. 31-VII-1591, fol. 399; leg. 400- 8-VII-1584, fols. 333-334. 
plasmada en una carta de pago redactada por el escribano ${ }^{116}$. De no efectuarse en la fecha indicada podía fijarse una cuantía diaria como salario para la persona que se encargase de cobrarlo ${ }^{117}$.

Los documentos zamoranos de esta época no abordaron sino excepcionalmente algunas eventualidades que podrían acabar con el funcionamiento de las compañías, como los casos de enfermedad o fallecimiento de alguno de los socios. En la de Bernardo López, vecino de Zamora, y Antonio López de Araújo, vecino de Vigo, para comerciar con pescados y «otras cosas», la sociedad quedaría finiquitada en caso de muerte de cualquiera de los socios ${ }^{118}$. Si había una continuidad por los descendientes del socio fallecido -caso de la viuda e hijos de Luis de Valencia-se redactaban nuevas escrituras bajo prácticamente las mismas condiciones ${ }^{119}$.

Algunas de ellas concluyeron antes de tiempo por el comportamiento irregular de uno de los socios. Fue el caso de la formada por Antonio Maniego, vecino de Morales, y Francisco Rodríguez Montesino, escribano y mercader de hierro, creada para comercializar con cardón y gualda. La ruptura se fraguó porque Antonio había vendido mercancías al fiado, algunas de ellas a parientes suyos, «no habiéndolo de hacer así, sino luego pagar». El socio capitalista, Francisco, se conformó en este caso con la devolución del capital monetario invertido ${ }^{120}$.

Si bien la rentabilidad de los negocios de estas sociedades no es objeto de análisis de este trabajo, se puede interpretar la continuidad de algunos mercaderes -Juan de Astorga, Bartolomé Villalpando, Antonio de Villapando, Luis de Valencia o Bernardo López- en el ámbito del comercio a lo largo de los años como un síntoma de que sus actividades resultaban lucrativas. Contamos con escasa información al respecto al no haberse conservado, como ya hemos indicado, los libros de contabilidad y al no ofrecernos algunos de los documentos de transacción, caso de las citadas cartas de pago, datos sobre los márgenes de ganancias. En el caso de la compañía entre doña María Guedeja, Hernando García y María Álvarez,

116. AHPZa, PN, leg. 400. Carta de pago y «librequito» entre doña María de Guedeja y Hernando García, mercader, fol. 391; leg. 520. 11-VII-1596. Finiquito de la compañía de Bernardo López, mercader de Zamora, y Antonio López de Araúxo, vecino de Vigo, fol. 475; leg. 521. 6-VI-1597. Finiquito de la compañía de Luis de Valencia, mercader, vecino de Zamora, y Fernando de Acayna, vecino de Pontevedra, fol. 693; leg. 601. 22-VII-1586. Escritura de «librequito» para Bartolomé de Villapando, mercader, vecino de Zamora, fol. 498.

117. En el contrato de Catalina de Rojas, vecina de Bayona, y Luis de Valencia, mercader zamorano, quedaría fijada en 500 maravedíes diarios en concepto del viaje de ida, vuelta y estancia. AHPZa, PN, leg. 681. 4-VII-1599, fol. 526.

118. AHPZa, PN, leg. 518. 6-VII-1594, fols. 336-337.

119. Probablemente se debiera a que, como ha indicado José Martínez Gijón, la inserción de los descendientes del finado no se interpretaba como una continuidad de la compañía sino como una renovación. MARTínez GIJón, J.: La compañia mercantil en Castilla hasta las Ordenanzas del Consulado de Bilbao de 1737. Legislación y doctrina. Sevilla, 1979, p. 258.

120. AHPZa, PN, leg. 540. 31-III-1598, fols. 184-185. 
vecinos de Zamora, establecida para comerciar con paños, sedas, cera, azúcar y otras mercadurías, los beneficios para la primera fueron del 8,15 por ciento sobre el capital en efectivo invertido, una cifra por encima de lo que podían proporcionarle rentas fijas, caso de los juros. Esta rentabilidad resulta de las más bajas entre las que contamos con noticias. En la sociedad formada por Antonio Maniego y Francisco Rodríguez Montesino el margen de ganancias fue superior, compraban la arroba de gualda a 3,5 reales y la vendían a 5 reales (un 33,3 por ciento más) y el cardón lo adquirían a 3 reales el millar, dándole salida a un precio de entre 4 y 5 reales (entre un 25 y un 66 por ciento más). Evidentemente se trataba de un beneficio bruto ya que habría que descontar de ese porcentaje los gastos de transporte ${ }^{121}$. El testamento de Joán Destrín, francés, del obispado de Claramonte, estante en Zamora, aludía a la compañía que había fundado con Jaques Borque con un capital de 6.500 reales y les había dado un beneficio de 1.200 reales, es decir, algo más de un 18 por ciento ${ }^{122}$. Lo que es un hecho constatable es que quienes mostraron una mayor continuidad en los negocios, como el citado Luis de Valencia, lograron obtener fortunas que les permitieron incluso la fundación de capellanías ${ }^{123}$.

\section{Consideraciones finales}

Si bien las compañías zamoranas manifiestan similitudes con las de la península -predominio de asociaciones con dos compañeros, disparidad de capitales movilizados, inexistencia en algunos casos de capital social valorado monetariamente en el momento de su constitución, distribución de ganancias y pérdidas en proporción al capital en efectivo aportado; no obstante, mantuvieron otras características singulares como fueron la escasa presencia de elementos religiosos en la redacción de los documentos frente a otras zonas -aunque para épocas distintas- ${ }^{124}$;

\section{Ibidem.}

122. En las estudiadas por Pegerto Saavedra para Galicia para el siglo XVIII los beneficios anuales oscilaron entre el 0,73 y el 35 por ciento. En las comandas barcelonesas durante la Baja Edad Media estuvieron entre el 20 y el 30 por ciento, llegando incluso al 50 por ciento; en Burgos entre el 20 y el 25 por ciento en época de los Reyes Católicos. AHPZa, PN, leg. 616. 28-VII-1593, fol. 359; SAAVEDRA FERNÁNDEZ, P.: «La renovación de los grupos burgueses en Galicia en la segunda mitad del siglo XVIII», en EnCiso Recio, L. M.: La burguesía española en la Edad Moderna. Tomo III. Valladolid, 1996, pp. 1346-1367; Madurell y Marimón, J. M. y García SAnZ, A.: Comandas comerciales barcelonesas de la Baja Edad Media. Barcelona, 1973, p. 123; CAunedo Del Potro, B.: «Comercio y hombres de negocios castellanos en tiempos de los Reyes Católicos. Técnicas y aprendizaje», en CASAdo Alonso, H. y García-Baquero, A. (Eds.): Op. cit., p. 265 y «Compañías mercantiles castellanas a fines de la Edad Media», Medievalismo, 3 (1993), p. 53.

123. Mediante su testamento observamos una diversificación en sus negocios ya que invirtió en juros y arrendó labranzas. AHPZa, PN, leg. 523. 1-X-1599, fols. 925-932.

124. En Valencia perviven fórmulas religiosas estereotipadas, invocaciones o adopción de protectores en uno de cada cuatro documentos incluso en el siglo XVIII. En Zamora solo encontramos dos casos: 
la total ausencia de referencias a jueces árbitros en los contratos de constitución para dirimir las diferencias en el seno de estas sociedades a fin de evitar acudir a los tribunales -una práctica presente en otras urbes- ${ }^{125}$; la limitada participación de familiares en los negocios -apenas en un 7 por ciento de las sociedades- ${ }^{126}$; la restringida aportación de elementos de capital societario en géneros -fundamentalmente por estar orientadas a productos perecederos- o en efectos mercantiles; su corta duración, inferior a las establecidas en otras ciudades ${ }^{127}$; y, sobre todo, la ausencia de extranjeros, bien en calidad de socios o de factores, tan habituales en otras ciudades, especialmente las costeras ${ }^{128}$.

Por otro lado se puede apreciar el papel de Zamora como centro importante de comercialización del pescado que llegaba de los ríos y puertos gallegos, así como de las zonas portuarias portuguesas. No se trataba de una mercancía destinada exclusivamente a los usuarios de la ciudad a pesar del crecimiento demográfico de la urbe a lo largo del siglo $\mathrm{xvI}^{129}$. Las escrituras de obligación de los proto-

el de Isabel de Cobillos, Gregorio Sánchez, andador, y Francisca de Villalpando que se concertaron para fundar una compañía «...a servicio de Dios y de su bendita Madre»; y el de Antonio Morales Varejón y Francisco Martínez, quienes aludieron a los beneficios o pérdidas como «el ganar o perder que Dios le diere». AHPZa, PN, leg. 439. 31-XII-1579, fols. 1137-1138; leg. 400. 8-VII-1584, fols. 333-334. Franch Benavent, R.: Op. cit., p. 259.

125. Ver. Basas Fernández, M.: Art. cit., p. 391. Bustos Rodríguez, M.: Cádiz en el sistema Atlántico. La ciudad, sus comerciantes y la actividad mercantil (1650-1830). Cádiz, 2005, p. 476.

126. Sigue la línea de las compañías de Medina del Campo aunque en un porcentaje muy inferior, y difiere de las segovianas en la Baja Edad Media o de las sevillanas, canarias, toledanas o marsellesas para esta misma centuria donde el carácter familiar, los factores de sangre o el parentesco tuvieron un papel decisivo al igual que en otros países. LOBO CABRERA, M.: El comercio canario europeo bajo Felipe II. Gran Canaria, 1988, pp. 18 y 85; CARRIÈre, Ch.: Négociants marseillais au XvIIIe siècle: Contribution à l'étude des économies maritimes. Marsella, 1973, pp. 880-885; AsEnJo GonZÁLEZ, M.: «Participación de las mujeres en las compañías comerciales castellanas a fines de la Edad Media. Los mercaderes segovianos» en MuÑoz FernándeZ, Á. y SEGURA Graíño, C.: El trabajo de las mujeres en la Edad Media Hispana. Madrid, 1988, p. 229; RodríGueZ DE Gracia, H.: «Mercaderes y asociaciones mercantiles en el comercio toledano de la seda en la segunda mitad del siglo XVII». Hispania. 210 (2002), p. 92; BRATCHEL, M. E.: «Italian merchant organization and business in relationships in early Tudor London» en Subrahmanyam, S. (ed.).: Merchant Networks in the Early Modern World. Aldershot, 1996, pp. 6 y 18.

127. Por su corta duración y capital limitado mantiene paralelismos con las toscanas aunque en esta zona estuvieron dedicadas fundamentalmente al ámbito textil. Grubb, J.: Provincial families of the Renaissance: private and public life in Veneto. Baltimore, 1996, p. 110.

128. Ramos Medina, M. ${ }^{a}$ D.: «Los mercaderes extranjeros en Madrid: Compañías y negocios (1648-1678)», en Villar García, M. B. y Pezzi Cristóbal, P. (eds.): Los extranjeros en la España Moderna. Málaga: 2003, p. 559; CRUSELLES, E.: «Hombres de negocios y mercaderes valencianos en el tránsito al mundo moderno» y MONTOJO MonTOJO, V.: «La burguesía mercantil en el sureste español: el ejemplo de Cartagena» en ENCISO Recio, L. M.: Op. cit. pp. 623-631 y 659-669 (respectivamente).

129. Conforme al censo de 1530 contaba con 837 vecinos que ascendieron a 2150 en 1561, según los datos de la renta de alcabala, para descender a 1695 en 1591. Ver Díaz MedinA, A.: «La población de Zamora en el siglo XvI». Studia Zamorensia, 1 (1980), pp. 67-118. 
colos notariales nos permiten constatar su redistribución hacia otras ciudades españolas caso de Salamanca, Madrid y Segovia ${ }^{130}$. M. F. Ladero Quesada en su estudio sobre la urbe zamorana para la época de los Reyes Católicos subrayaba el aparente elevado consumo de esta mercancía para una ciudad interior como esta, llegando a la conclusión del que el pescado constituía un elemento fundamental, casi de primera necesidad, de la dieta de los habitantes de la jurisdicción zamorana, pero no constata su salida hacia otros mercados ${ }^{131}$. La fundación de un número elevado de compañías dedicadas a la comercialización de pescado en el último tercio del siglo xvi corrobora la dinámica apreciada en las averiguaciones de alcabalas para esta centuria: el crecimiento de la renta del pescado que pasó, frente a otras rentas, del octavo lugar al tercero en el año 1600 en el monto total de ingresos municipales ${ }^{132}$.

Lapeyre en su estudio sobre las listas de aduanas para los diezmos de la mar referentes a las últimas cuatro décadas del siglo Xvi se sorprendía de la ausencia de mercaderes zamoranos lo cual le llevaba a «admitir» que Zamora, junto a Salamanca o León, no contaban más que con comerciantes que hacían compras en las ferias de Castilla. Este estudio pone de manifiesto cómo las compañías zamoranas sobrepasaron este estrecho marco geográfico y subraya la necesidad de recurrir a otras fuentes de información para calibrar la importancia real del comercio en la urbe ${ }^{133}$. Cuando se conozca el volumen y la evolución de la comercialización de pescado en las ferias castellanas se podrá constatar si los comerciantes zamoranos asumieron en parte la posible pérdida de mercado de ellas. De ser así se explicaría por qué los mercaderes de Zamora, que hasta entonces habían actuado de una manera individual, se unieron en compañías para conseguir el capital necesario que les permitiera afrontar un ámbito de negocios más amplio ${ }^{134}$.

130. AHPZa, PN, leg. 523. 13-IV-1599. Escritura de obligación para Juan Sánchez, tratante, vecino de Segovia, fols. 198-204.

131. Ladero Quesada, M. F.: La ciudad de Zamora en época de los Reyes Católicos: Economía y Gobierno. Zamora, 1991, pp. 78-79.

132. Alba López, J. C. y Rueda Fernández, J. C.: «La industria y el comercio en la Edad Moderna» en VV. AA.: Historia de Zamora. Tomo II. Zamora, 1995, pp. 195-196.

133. LAPEYRE, H.: El comercio exterior de Castilla a través de las aduanas de Felipe II. Valladolid, 1981, p. 97.

134. Felipe Ruiz Martín subraya que desde el último cuarto del siglo XvI las ferias castellanas redujeron su volumen de negocios. B. Yun Casalilla constata igualmente un descenso en el arrendamiento del peso de Medina de Rioseco, uno de los centros de destino del pescado gallego, entre 1578 y 1581 que volvió a recuperarse en las dos últimas décadas. Ninguno de los dos historiadores ofrece datos específicos sobre la evolución del comercio del pescado para corroborar nuestra hipótesis. RuIZ MarTín, F.: «Las ferias de Castilla» en Lorenzo Sanz, E.: Op. cit., pp. 282-287; Yun Casalilla, B.: «Ferias y mercados: indicadores y coyuntura comercial en la vertiente norte del Duero: siglos XVI y XVII», Investigaciones históricas, 4 (1983), pp. 51-82. 
APÉNDICE

Compañías comerciales fundadas en la ciudad de Zamora (1575-1600)

\begin{tabular}{|c|c|c|c|c|c|c|c|c|c|}
\hline 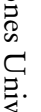 & Año & Socios & $\begin{array}{l}\text { Cat. Socio- } \\
\text { profesional }\end{array}$ & $\begin{array}{l}\text { Localidad de } \\
\text { procedencia }\end{array}$ & Capital (en reales) & $\begin{array}{c}\% \text { de reparto } \\
\text { (ganancia o } \\
\text { pérdida) }\end{array}$ & Objeto social & $\begin{array}{c}\text { Vigencia } \\
\text { de la Cía. } \\
\text { (meses) }\end{array}$ & $\begin{array}{c}\text { Saben firmar } \\
\text { los socios }\end{array}$ \\
\hline 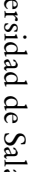 & 1575 & $\begin{array}{l}\text { Alonso, Francisco } \\
\text { Gumiel, Pedro de } \\
\text { Pérez, Juan }\end{array}$ & $\begin{array}{l}\text { Mercader } \\
\text { Mercader }\end{array}$ & $\begin{array}{l}\text { Zamora } \\
\text { Zamora } \\
\text { Tordesillas }\end{array}$ & $\begin{array}{l}\mathrm{SD} \\
\mathrm{SD} \\
\mathrm{SD}\end{array}$ & $\begin{array}{l}1 / 3 \\
1 / 3 \\
1 / 3\end{array}$ & Pescado & 12 & $\begin{array}{l}\text { Sí } \\
\text { Sí } \\
\text { Sí }\end{array}$ \\
\hline & 1576 & $\begin{array}{l}\text { Morales, Antonio } \\
\text { Delgada, Isabel (matrim.) } \\
\text { Rodríguez, Juan }\end{array}$ & Mercader & $\begin{array}{l}\text { Zamora } \\
\text { Zamora } \\
\text { Salamanca }\end{array}$ & $\begin{array}{r}15.000 \\
15.000\end{array}$ & $\begin{array}{l}3 / 5 \\
2 / 5\end{array}$ & Pescado, O.M. & 12 & $\begin{array}{l}\text { Sí } \\
\text { No } \\
\text { Sí }\end{array}$ \\
\hline . & 1578 & $\begin{array}{l}\text { Morales, Antonio } \\
\text { Rodríguez, Bernardo } \\
\text { Gumiel, Pedro } \\
\text { Rúa, Bartolomé de la }\end{array}$ & $\begin{array}{l}\text { Mercader } \\
\text { Mercader } \\
\text { Mercader }\end{array}$ & $\begin{array}{l}\text { Zamora } \\
\text { Zamora } \\
\text { Zamora } \\
\text { Bayona }\end{array}$ & $\begin{array}{c}11.000 \text { (entre los tres) } \\
11.000\end{array}$ & $1 / 2$ & Pescado & 6 & $\begin{array}{l}\text { Sí } \\
\text { Sí } \\
\text { Sí } \\
\text { Sí }\end{array}$ \\
\hline 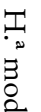 & 1578 & $\begin{array}{l}\text { Quirós, Pedro de } \\
\text { Fontefría, Gregorio de }\end{array}$ & Mercader & $\begin{array}{l}\text { Zamora } \\
\text { Vigo }\end{array}$ & $\begin{array}{l}6.000 \\
6.000\end{array}$ & $\begin{array}{l}1 / 2 \\
1 / 2\end{array}$ & Pescado & 12 & $\begin{array}{l}\text { Sí } \\
\text { Sí }\end{array}$ \\
\hline 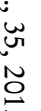 & 1578 & $\begin{array}{l}\text { Fontefría, Gregorio de } \\
\text { Rivera, Ana de }\end{array}$ & & $\begin{array}{l}\text { Vigo } \\
\text { Zamora }\end{array}$ & $\begin{array}{l}5.500 \\
5.500\end{array}$ & $\begin{array}{l}1 / 2 \\
1 / 2\end{array}$ & Pescado & 12 & $\begin{array}{l}\text { Sí } \\
\text { No }\end{array}$ \\
\hline 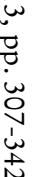 & 1579 & $\begin{array}{l}\text { Astorga, Juan de } \\
\text { Valencia, Hernando de } \\
\text { Villalpando, Antonio (El Mozo) }\end{array}$ & Mercader & $\begin{array}{l}\text { Zamora } \\
\text { Zamora } \\
\text { Zamora }\end{array}$ & 3.000 & $\begin{array}{l}1 / 3 \\
1 / 3 \\
1 / 3\end{array}$ & Pescado & 6 & $\begin{array}{l}\text { Sí } \\
\text { Sí } \\
\text { Sí }\end{array}$ \\
\hline
\end{tabular}




\begin{tabular}{|c|c|c|c|c|c|c|c|c|}
\hline 1579 & $\begin{array}{l}\text { Astorga, Juan de } \\
\text { Rocha, Antonio de la }\end{array}$ & Mercader & $\begin{array}{l}\text { Zamora } \\
\text { Bayona }\end{array}$ & $\begin{array}{l}6.000 \\
3.300 \\
\end{array}$ & $\begin{array}{l}2 / 3 \\
1 / 3 \\
\end{array}$ & Pescado & $\begin{array}{l}12 \text { (duró } \\
7 \text { meses) }\end{array}$ & $\begin{array}{l}\text { Sí } \\
\text { Sí }\end{array}$ \\
\hline 1579 & $\begin{array}{l}\text { Astorga, Juan de } \\
\text { Rocha, Antonio de la }\end{array}$ & Mercader & $\begin{array}{l}\text { Zamora } \\
\text { Bayona }\end{array}$ & $\begin{array}{l}6.000 \\
3.300\end{array}$ & $\begin{array}{l}2 / 3 \\
1 / 3\end{array}$ & Pescado & 12 meses & $\begin{array}{l}\text { Sí } \\
\text { Sí }\end{array}$ \\
\hline 1579 & $\begin{array}{l}\text { Cubillos, Isabel de } \\
\text { Sánchez, Gregorio } \\
\text { Castro, Francisca de } \\
\text { Franco, Antonio }\end{array}$ & Andador & $\begin{array}{l}\text { Zamora } \\
\text { Zamora } \\
\text { Zamora } \\
\text { Galicia }\end{array}$ & $\begin{array}{l}1.000 \\
1.000 \\
2.000\end{array}$ & $\begin{array}{l}1 / 3 \\
1 / 3 \\
1 / 3\end{array}$ & Pescado, O.M. & 6 & $\begin{array}{l}\text { No } \\
\text { Sí } \\
\text { No } \\
\text { SD }\end{array}$ \\
\hline 1579 & $\begin{array}{l}\text { Guedeja, Da María } \\
\text { García, Hernando }\end{array}$ & Mercader & $\begin{array}{l}\text { Zamora } \\
\text { Zamora }\end{array}$ & 14.300 & $\begin{array}{l}1 / 2 \\
1 / 2 \\
\end{array}$ & $\begin{array}{l}\text { Paños, seda, } \\
\text { cera, azúcar }\end{array}$ & 36 & $\begin{array}{l}\text { Sí } \\
\text { Sí }\end{array}$ \\
\hline 1581 & $\begin{array}{l}\text { Osorio, Alonso } \\
\text { Valladolid, Catalina de } \\
\text { Marcos de Medina (su hijo) }\end{array}$ & & $\begin{array}{l}\text { Zamora } \\
\text { Zamora } \\
\text { Zamora }\end{array}$ & $\begin{array}{l}6.287 \\
6.287\end{array}$ & $\begin{array}{l}1 / 2 \\
1 / 2\end{array}$ & Ganado & SD & $\begin{array}{l}\text { Sí } \\
\text { No }\end{array}$ \\
\hline 1581 & $\begin{array}{l}\text { Astorga, Juan de } \\
\text { Pérez, Alonso }\end{array}$ & Mercader & $\begin{array}{l}\text { Zamora } \\
\text { La Guardia }\end{array}$ & $\begin{array}{l}\mathrm{SD} \\
\mathrm{SD}\end{array}$ & $\begin{array}{l}2 / 3 \\
1 / 3 \\
\end{array}$ & Pescado, O.M. & 12 & $\begin{array}{l}\text { Sí } \\
\text { Sí }\end{array}$ \\
\hline 1581 & $\begin{array}{l}\text { Rodríguez, Bernardo } \\
\text { Peña, Pedro de la } \\
\text { Costilla, Alonso de }\end{array}$ & & $\begin{array}{l}\text { Zamora } \\
\text { Peñaranda } \\
\text { Bayona }\end{array}$ & $\begin{array}{c}10.000 \text { (entre } 2) \\
4.400\end{array}$ & $\begin{array}{l}3 / 5 \text { (para los } \\
\text { dos), } 4 / 5,4 / 5 \\
\\
2 / 5,1 / 4,1 / 5\end{array}$ & $\begin{array}{l}\text { Pescado, cera } \\
\text { azúcar, «Brasil» }\end{array}$ & 12 & $\begin{array}{l}\text { Sí } \\
\text { No } \\
\text { Sí }\end{array}$ \\
\hline 1581 & $\begin{array}{l}\text { Rodríguez, Bernardo } \\
\text { González, Alonso }\end{array}$ & & $\begin{array}{l}\text { Zamora } \\
\text { La Guardia }\end{array}$ & $\begin{array}{l}6.000 \\
3.000\end{array}$ & $\begin{array}{l}2 / 3 \\
1 / 3\end{array}$ & Pescado & 12 & $\begin{array}{l}\text { Sí } \\
\text { Sí }\end{array}$ \\
\hline
\end{tabular}




\begin{tabular}{|c|c|c|c|c|c|c|c|c|}
\hline 1581 & $\begin{array}{l}\text { Vergas, Antonio de } \\
\text { Rocha, Antonio de }\end{array}$ & $\begin{array}{l}\text { Mercader } \\
\text { Mercader }\end{array}$ & $\begin{array}{l}\text { Zamora } \\
\text { Bayona }\end{array}$ & $\begin{array}{l}6.000 \\
3.300\end{array}$ & $\begin{array}{l}2 / 3 \\
1 / 3\end{array}$ & Pescado & 12 & $\begin{array}{l}\text { Sí } \\
\text { Sí }\end{array}$ \\
\hline 1581 & $\begin{array}{l}\text { Vergas, Antonio de } \\
\text { Peña, Antonio de la } \\
\text { Rocha, Antonio de } \\
\text { Ceballos, Pedro de }\end{array}$ & Mercader & $\begin{array}{l}\text { Zamora } \\
\text { Peñaranda } \\
\text { Zamora }\end{array}$ & $\begin{array}{l}18.000 \\
2.000 \\
3.000\end{array}$ & $\begin{array}{l}\mathrm{SD} \\
1 / 6 \\
\mathrm{SD} \\
\mathrm{SD}\end{array}$ & Pescado, O.M. & 12 & $\begin{array}{l}\text { Sí } \\
\text { No } \\
\text { SD } \\
\text { SD }\end{array}$ \\
\hline 1581 & $\begin{array}{l}\text { Vergas, Antonio de } \\
\text { Toro, Luis de }\end{array}$ & Mercader & $\begin{array}{l}\text { Zamora } \\
\text { Peñaranda }\end{array}$ & 4.000 & $\begin{array}{c}\text { SD } \\
500 \text { Reales }\end{array}$ & SD & 9 & $\begin{array}{l}\text { Sí } \\
\text { Sí }\end{array}$ \\
\hline 1582 & $\begin{array}{l}\text { García, Diego } \\
\text { Medina, Antonio } \\
\text { Prieto, Francisco }\end{array}$ & $\begin{array}{l}\text { Mercader } \\
\text { Mercader }\end{array}$ & $\begin{array}{l}\text { Zamora } \\
\text { Zamora } \\
\text { Villamor de los } \\
\text { Escuderos } \\
\end{array}$ & $\begin{array}{l}\mathrm{SD} \\
\mathrm{SD} \\
\mathrm{SD}\end{array}$ & $\begin{array}{l}1 / 3 \\
1 / 3 \\
1 / 3\end{array}$ & Vino & 9 & $\begin{array}{l}\text { Sí } \\
\text { Sí } \\
\text { Sí }\end{array}$ \\
\hline 1582 & $\begin{array}{l}\text { Vázquez, Francisca } \\
\text { Mielgo, Sebastián } \\
\text { Peinado, Juan }\end{array}$ & & $\begin{array}{l}\text { Zamora } \\
\text { Muelas } \\
\text { Zamora }\end{array}$ & 2.200 & $\begin{array}{l}1 / 3 \\
1 / 3 \\
1 / 3\end{array}$ & Pescado & SD & $\begin{array}{l}\text { No } \\
\text { Sí } \\
\text { No }\end{array}$ \\
\hline 1583 & $\begin{array}{l}\text { Villalpando, Bartolomé de } \\
\text { Martínez, Gonzalo }\end{array}$ & Mercader & $\begin{array}{l}\text { Zamora } \\
\text { Vigo }\end{array}$ & $\begin{array}{l}12.000 \\
6.000\end{array}$ & $\begin{array}{l}3 / 5 \\
2 / 5\end{array}$ & Pescado, O.M. & 12 & $\begin{array}{l}\text { Sí } \\
\text { Sí }\end{array}$ \\
\hline 1583 & $\begin{array}{l}\text { Villalpando, Bartolomé de } \\
\text { Zamora, Francisco de }\end{array}$ & Mercader & $\begin{array}{l}\text { Zamora } \\
\text { Castro Urdiales }\end{array}$ & $\begin{array}{l}6.000 \\
\mathrm{SD}\end{array}$ & $\begin{array}{l}2 / 3 \text { y } 3 / 4 \\
1 / 3 \text { y } 1 / 4\end{array}$ & Pescado, O.M. & 12 & $\begin{array}{l}\text { Sí } \\
\text { Sí }\end{array}$ \\
\hline 1583 & $\begin{array}{l}\text { Villalpando, Bartolomé de } \\
\text { Gómez de Villapando, Alon- } \\
\text { so }\end{array}$ & Mercader & $\begin{array}{l}\text { Zamora } \\
\text { Galicia }\end{array}$ & SD & $\begin{array}{l}2 / 3 \\
1 / 3\end{array}$ & Pescado, O.M. & 12 & Sí \\
\hline
\end{tabular}




\begin{tabular}{|c|c|c|c|c|c|c|c|c|}
\hline 1583 & $\begin{array}{l}\text { Villalpando, Bartolomé de } \\
\text { Bave, Rodrigo de }\end{array}$ & $\begin{array}{l}\text { Mercader } \\
\text { Mercader }\end{array}$ & $\begin{array}{l}\text { Zamora } \\
\text { Zamora }\end{array}$ & SD & $\mathrm{SD}$ & Pescado, O.M. & $\mathrm{SD}$ & $\begin{array}{l}\text { Sí } \\
\text { Sí }\end{array}$ \\
\hline 1583 & $\begin{array}{l}\text { Villalpando, Bartolomé de } \\
\text { Hernández, Andrés }\end{array}$ & Mercader & $\begin{array}{l}\text { Zamora } \\
\text { Lugo }\end{array}$ & $\begin{array}{r}14.000 \\
6.000\end{array}$ & $\begin{array}{l}3 / 5 \\
2 / 5\end{array}$ & Pescado, O.M. & 12 & $\begin{array}{l}\text { Sí } \\
\text { Sí }\end{array}$ \\
\hline 1583 & $\begin{array}{l}\text { Villalpando, Bartolomé de } \\
\text { Castro, Antonio de }\end{array}$ & Mercader & $\begin{array}{l}\text { Zamora } \\
\text { Villamayor }\end{array}$ & $\begin{array}{l}6.000 \\
3.000\end{array}$ & $\begin{array}{l}2 / 3 \\
1 / 3\end{array}$ & Pescado & 14 & $\begin{array}{l}\text { Sí } \\
\text { No }\end{array}$ \\
\hline 1583 & $\begin{array}{l}\text { Rodríguez, Bernardo } \\
\text { Mesego, Fernando de }\end{array}$ & Mercader & $\begin{array}{l}\text { Zamora } \\
\text { Bayona }\end{array}$ & $\begin{array}{l}6.000 \\
3.000\end{array}$ & $\begin{array}{l}2 / 3 \\
1 / 3\end{array}$ & Pescado & 12 & $\begin{array}{l}\text { Sí } \\
\text { Sí }\end{array}$ \\
\hline 1584 & $\begin{array}{l}\text { Astorga, Juan de } \\
\text { Villalpando, Antonio }\end{array}$ & Mercader & $\begin{array}{l}\text { Zamora } \\
\text { Bayona }\end{array}$ & $\begin{array}{l}\mathrm{LN} \\
1.000\end{array}$ & $\begin{array}{l}2 / 3 \\
1 / 3\end{array}$ & $\begin{array}{l}\text { Cera, pescado, } \\
\text { azúcar, aceite, } \\
\text { O.M. }\end{array}$ & 12 & $\begin{array}{l}\text { Sí } \\
\text { Sí }\end{array}$ \\
\hline 1584 & $\begin{array}{l}\text { Morales Varejón, Antonio de } \\
\text { Patino, Bartolomé }\end{array}$ & & $\begin{array}{l}\text { Zamora } \\
\text { O Carril }\end{array}$ & $\begin{array}{l}12.000 \\
12.000\end{array}$ & $\begin{array}{l}1 / 2 \\
1 / 2\end{array}$ & Pescado & 12 & $\begin{array}{l}\text { Sí } \\
\text { Sí }\end{array}$ \\
\hline 1584 & $\begin{array}{l}\text { Villalpando, Bartolomé de } \\
\text { Hernández, Andrés }\end{array}$ & Mercader & $\begin{array}{l}\text { Zamora } \\
\text { Lugo }\end{array}$ & $\begin{array}{l}12.000 \\
6.000\end{array}$ & $\begin{array}{l}3 / 5 \\
2 / 5\end{array}$ & Pescado & 12 & $\begin{array}{l}\text { Sí } \\
\text { Sí }\end{array}$ \\
\hline 1584 & $\begin{array}{l}\text { Morales Varejón, Antonio de } \\
\text { Martínez, Francisco }\end{array}$ & $\begin{array}{l}\text { Mercader } \\
\text { Mercader }\end{array}$ & $\begin{array}{l}\text { Zamora } \\
\text { La Guardia }\end{array}$ & 1.100 & $\begin{array}{l}2 / 5 \text { y } 1 / 5 \\
3 / 5 \text { y } 4 / 5\end{array}$ & Pescado & 12 & $\begin{array}{l}\text { Sí } \\
\text { SD }\end{array}$ \\
\hline 1585 & $\begin{array}{l}\text { Morales Varejón, Antonio de } \\
\text { López, Juan }\end{array}$ & Mercader & $\begin{array}{l}\text { Zamora } \\
\text { Vigo }\end{array}$ & $\begin{array}{l}\mathrm{LN} \\
8.000\end{array}$ & $\begin{array}{l}3 / 5 \\
2 / 5\end{array}$ & Pescado & 12 & $\begin{array}{l}\text { Sí } \\
\text { Sí }\end{array}$ \\
\hline 1585 & $\begin{array}{l}\text { Peña, María de la } \\
\text { Sánchez, Pedro } \\
\text { Pérez, Alonso }\end{array}$ & & $\begin{array}{l}\text { Zamora } \\
\text { Zamora } \\
\text { La Guardia }\end{array}$ & $\begin{array}{c}\mathrm{SD} \\
\mathrm{SD} \\
\mathrm{LQP}\end{array}$ & $\begin{array}{l}\mathrm{SD} \\
\mathrm{SD} \\
2 / 5\end{array}$ & Pescado & 12 & $\begin{array}{l}\text { No } \\
\text { Sí } \\
\text { Sí }\end{array}$ \\
\hline
\end{tabular}




\begin{tabular}{|c|c|c|c|c|c|c|c|c|}
\hline 1585 & $\begin{array}{l}\text { Valencia, Luis de y compa- } \\
\text { ñeros } \\
\text { Costilla, Alonso }\end{array}$ & $\begin{array}{l}\text { Mercader } \\
\text { Mercader }\end{array}$ & $\begin{array}{l}\text { Zamora } \\
\text { Bayona }\end{array}$ & $2.000+\mathrm{LN}$ & $2 / 5$ & Pescado & 12 & Sí \\
\hline 1586 & $\begin{array}{l}\text { Villalpando, Bartolomé de } \\
\text { Hernández, Antonio }\end{array}$ & Mercader & $\begin{array}{l}\text { Zamora } \\
\text { Zamora }\end{array}$ & $\begin{array}{l}\mathrm{LN} \\
5.000 \\
\end{array}$ & $\begin{array}{l}5 / 7 \\
2 / 7\end{array}$ & Todo género & 12 & Sí \\
\hline 1586 & $\begin{array}{l}\text { Villalpando, Bartolomé de } \\
\text { Hernández, Andrés }\end{array}$ & Mercader & $\begin{array}{l}\text { Zamora } \\
\text { Vigo }\end{array}$ & $\begin{array}{c}3.000+\mathrm{LN} \\
8.000\end{array}$ & $\begin{array}{l}2 / 3 \\
1 / 3\end{array}$ & Pescados, O.M. & 12 & Sí \\
\hline 1586 & $\begin{array}{l}\text { Valencia, Luis de } \\
\text { Villalpando, Antonio }\end{array}$ & Mercader & $\begin{array}{l}\text { Zamora } \\
\text { Bayona }\end{array}$ & $\begin{array}{l}\mathrm{LN} \\
9.000\end{array}$ & $\begin{array}{l}3 / 5,4 / 5 \text { y } 1 / 2 \\
2 / 5,1 / 5 \text { y } 1 / 2\end{array}$ & $\begin{array}{l}\text { Pescado, O.M. } \\
\text { (cera, azúcar, } \\
\text { becerros, } \\
\text { paños, cam- } \\
\text { panil, trigo) }\end{array}$ & 11 & Sí \\
\hline 1586 & $\begin{array}{l}\text { Valencia, Luis de } \\
\text { Pérez, Alonso }\end{array}$ & Mercader & $\begin{array}{l}\text { Zamora } \\
\text { La Guardia }\end{array}$ & $\begin{array}{l}\mathrm{SD} \\
\mathrm{SD}\end{array}$ & $\begin{array}{l}3 / 5 \\
2 / 5\end{array}$ & Pescado & 12 & $\begin{array}{l}\text { Sí } \\
\text { Sí }\end{array}$ \\
\hline 1586 & $\begin{array}{l}\text { Zamora, Alonso de } \\
\text { Herrera, Juan de } \\
\text { Sánchez, Pedro }\end{array}$ & Mercader & $\begin{array}{l}\text { Carbajales } \\
\text { Carbajales } \\
\text { Zamora }\end{array}$ & $\begin{array}{c}15.000 \text { (entre 2) } \\
5.000\end{array}$ & $\begin{array}{c}3 / 4(\operatorname{los} \text { dos }) \\
1 / 4\end{array}$ & Ganado & 10 & $\begin{array}{l}\text { Sí } \\
\text { Sí }\end{array}$ \\
\hline 1587 & $\begin{array}{l}\text { Mesego, Fernando de } \\
\text { González de Silva, Diego }\end{array}$ & $\begin{array}{l}\text { Mercader } \\
\text { Mercader }\end{array}$ & $\begin{array}{l}\text { Bayona } \\
\text { Zamora }\end{array}$ & $\begin{array}{l}6.000 \\
\mathrm{LN}\end{array}$ & $\begin{array}{l}2 / 5 \\
3 / 5\end{array}$ & $\begin{array}{l}\text { Pescado, cera. } \\
\text { O.M. }\end{array}$ & 12 & Sí \\
\hline 1587 & $\begin{array}{l}\text { Sánchez, Pedro } \\
\text { Herrera, Juan de } \\
\text { Zamora, Alonso de } \\
\text { Hidalgo, Melchor }\end{array}$ & Mercader & $\begin{array}{l}\text { Zamora } \\
\text { Carbajales } \\
\text { Carbajales } \\
\text { Carbajales }\end{array}$ & $\begin{array}{l}5.500 \\
6.000 \\
6.000 \\
2.500\end{array}$ & $\begin{array}{l}1 / 4 \\
1 / 4 \\
1 / 4 \\
1 / 4\end{array}$ & Ganado & 12 & Sí \\
\hline
\end{tabular}




\begin{tabular}{|c|c|c|c|c|c|c|c|c|}
\hline 1587 & $\begin{array}{l}\text { Sánchez, Pedro } \\
\text { Bergas, Blanca de } \\
\text { Alonso, Francisco }\end{array}$ & Mercader & $\begin{array}{l}\text { Zamora } \\
\text { Zamora }\end{array}$ & $\begin{array}{l}13.000 \\
26.000 \\
13.000 \\
\end{array}$ & $\begin{array}{l}1 / 3 \\
1 / 3 \\
1 / 3\end{array}$ & $\begin{array}{l}\text { Pescado, azú- } \\
\text { car, ganado, } \\
\text { O.M. }\end{array}$ & 12 & $\begin{array}{l}\text { Sí } \\
\text { No } \\
\text { SD }\end{array}$ \\
\hline 1587 & $\begin{array}{l}\text { Alba, Felipa de } \\
\text { González de Silva, Diego }\end{array}$ & & $\begin{array}{l}\text { Vigo } \\
\text { Zamora }\end{array}$ & $\begin{array}{l}\mathrm{SD} \\
\mathrm{SD}\end{array}$ & $\begin{array}{l}\mathrm{SD} \\
\mathrm{SD}\end{array}$ & Pescado & 12 & $\begin{array}{l}\text { SD } \\
\text { Sí }\end{array}$ \\
\hline 1587 & $\begin{array}{l}\text { Villalpando, Bartolomé de } \\
\text { López, Bernardo } \\
\text { González, Melchor }\end{array}$ & & $\begin{array}{l}\text { Zamora } \\
\text { Zamora } \\
\text { Carbajales }\end{array}$ & $\begin{array}{l}5.000 \\
5.000\end{array}$ & $\begin{array}{l}1 / 3 \\
1 / 3 \\
1 / 3\end{array}$ & Ganado & 4 & $\begin{array}{l}\text { Sí } \\
\text { Sí } \\
\text { Sí }\end{array}$ \\
\hline 1587 & $\begin{array}{l}\text { Villalpando, Bartolomé de } \\
\text { Ovalle, Diego de }\end{array}$ & $\begin{array}{l}\text { Mercader } \\
\text { Mercader }\end{array}$ & $\begin{array}{l}\text { Zamora } \\
\text { Vigo }\end{array}$ & $\begin{array}{l}\text { SD } \\
\text { LQP }\end{array}$ & $\begin{array}{l}3 / 5 \\
2 / 5\end{array}$ & Pescado & 12 & $\begin{array}{l}\text { Sí } \\
\text { SD }\end{array}$ \\
\hline 1589 & $\begin{array}{l}\text { Vergas, Antonio } \\
\text { García, Hernán }^{135}\end{array}$ & $\begin{array}{l}\text { Mercader } \\
\text { Lencero }\end{array}$ & $\begin{array}{l}\text { Zamora } \\
\text { Zamora }\end{array}$ & 2.000 & $\begin{array}{l}1 / 2 \\
1 / 2\end{array}$ & Mercaderías & SD & $\begin{array}{l}\text { Sí } \\
\text { No }\end{array}$ \\
\hline 1589 & $\begin{array}{l}\text { Sánchez, Pedro } \\
\text { Bergas, Blanca de } \\
\text { Hidalgo, Melchor }\end{array}$ & Mercader & $\begin{array}{l}\text { Zamora } \\
\text { Zamora } \\
\text { Carbajales }\end{array}$ & $\begin{array}{l}7.000 \\
8.000 \\
3.000 \\
\end{array}$ & $\begin{array}{l}1 / 3 \\
1 / 3 \\
1 / 3\end{array}$ & Ganado, Sebo & 12 & $\begin{array}{l}\text { Sí } \\
\text { No } \\
\text { SD }\end{array}$ \\
\hline 1591 & $\begin{array}{l}\text { Valencia, Luis de } \\
\text { Cordero, Rodrigo }\end{array}$ & Mercader & $\begin{array}{l}\text { Zamora } \\
\text { Vigo }\end{array}$ & $\begin{array}{l}2.000 \\
1.000\end{array}$ & $\begin{array}{l}2 / 3 \\
1 / 3 \\
\end{array}$ & Pescado & 12 & $\begin{array}{l}\text { Sí } \\
\text { Sí }\end{array}$ \\
\hline 1592 & $\begin{array}{l}\text { López, Bernardo } \\
\text { Villalpando, Antonio }\end{array}$ & Mercader & $\begin{array}{l}\text { Zamora } \\
\text { Zamora }\end{array}$ & $\begin{array}{c}6.000+\mathrm{LN} \\
3.000\end{array}$ & $\begin{array}{l}5 / 7 \text { y } 1 / 2 \\
2 / 7 \text { y } 1 / 2\end{array}$ & $\begin{array}{l}\text { Pescado } \\
\text { Paños, O.M. }\end{array}$ & 12 & $\begin{array}{l}\text { Sí } \\
\text { Sí }\end{array}$ \\
\hline
\end{tabular}

135. Aunque aparece citado dos veces no se trata de la misma persona ya que el primero aparece como mercader y sabe firmar y este segundo como lencero y no sabe. 


\begin{tabular}{|c|c|c|c|c|c|c|c|c|}
\hline 1592 & $\begin{array}{l}\text { López, Bernardo } \\
\text { Castro, Francisco de }\end{array}$ & Mercader & $\begin{array}{l}\text { Zamora } \\
\text { Medina del } \\
\text { Campo }\end{array}$ & $\begin{array}{l}26.750 \\
12.000\end{array}$ & $\begin{array}{l}3 / 5 \text { y } 4 / 5 \\
2 / 5 \text { y } 1 / 5\end{array}$ & $\begin{array}{l}\text { Pescado, cera, } \\
\text { azúcar, «Bra- } \\
\text { sil», becerros, } \\
\text { O.M }\end{array}$ & 9 & Sí \\
\hline 1592 & $\begin{array}{l}\text { López, Bernardo } \\
\text { Rodríguez, Juan }\end{array}$ & $\begin{array}{l}\text { Mercader } \\
\text { Mercader }\end{array}$ & $\begin{array}{l}\text { Zamora } \\
\text { La Guardia }\end{array}$ & $\begin{array}{l}\text { LN } \\
\text { LN }\end{array}$ & $\begin{array}{l}3 / 5 \\
2 / 5\end{array}$ & Pescado & 12 & Sí \\
\hline 1593 & $\begin{array}{l}\text { López, Juan } \\
\text { López, Bernardo }\end{array}$ & $\begin{array}{l}\text { Mercader } \\
\text { Mercader }\end{array}$ & $\begin{array}{l}\text { Vigo } \\
\text { Zamora }\end{array}$ & $\begin{array}{l}8.000 \\
\mathrm{LN}\end{array}$ & $\begin{array}{l}2 / 5 \\
3 / 5\end{array}$ & «Mercadurías» & 12 & Sí \\
\hline 1594 & $\begin{array}{l}\text { López, Bernardo } \\
\text { López de Araúxo, Antonio }\end{array}$ & & $\begin{array}{l}\text { Zamora } \\
\text { Vigo }\end{array}$ & $\begin{array}{l}12.000 \\
7.000\end{array}$ & $\begin{array}{l}3 / 5 \\
2 / 5\end{array}$ & Pescado, O.M. & 12 & Sí \\
\hline 1594 & $\begin{array}{l}\text { López, Bernardo } \\
\text { Castro, Francisco }\end{array}$ & & $\begin{array}{l}\text { Zamora } \\
\text { Medina del } \\
\text { Campo }\end{array}$ & $\begin{array}{l}\mathrm{LN} \\
12.000\end{array}$ & $\begin{array}{l}3 / 5,4 / 5 \text { y } 3 / 4 \\
2 / 5,1 / 5 \text { y } 1 / 4\end{array}$ & $\begin{array}{l}\text { Pescado, cera, } \\
\text { azúcar, «Bra- } \\
\text { sil», O.M. }\end{array}$ & 12 & Sí \\
\hline 1594 & $\begin{array}{l}\text { Valencia, Luis de } \\
\text { Villalpando, Antonio }\end{array}$ & Mercader & $\begin{array}{l}\text { Zamora } \\
\text { Bayona }\end{array}$ & $\begin{array}{l}\mathrm{SD} \\
\mathrm{SD}\end{array}$ & $\begin{array}{c}3 / 5 \\
2 / 5 \text { y } 1 / 5\end{array}$ & Pescado, azúcar & 12 & Sí \\
\hline 1594 & $\begin{array}{l}\text { Cedrón, Juan } \\
\text { Entrala, Gaspar de }\end{array}$ & $\begin{array}{l}\text { Tejedor } \\
\text { Pisonero }\end{array}$ & $\begin{array}{l}\text { Zamora } \\
\text { Zamora }\end{array}$ & $\begin{array}{l}3.000 \\
1.000\end{array}$ & $\begin{array}{l}1 / 2 \\
1 / 2\end{array}$ & $\begin{array}{l}\text { Lana y «añi- } \\
\text { nos» }\end{array}$ & SD & No \\
\hline 1594 & $\begin{array}{l}\text { Zamora, Alonso de } \\
\text { Bave, Rodrigo de } \\
\text { Villacorta, Antonio de }\end{array}$ & & $\begin{array}{l}\text { Zamora } \\
\text { Zamora } \\
\text { Zamora }\end{array}$ & $\begin{array}{l}8.000 \\
8.000 \\
8.000\end{array}$ & $\begin{array}{l}1 / 3 \\
1 / 3 \\
1 / 3\end{array}$ & Ganado & 12 & Sí \\
\hline 1595 & $\begin{array}{l}\text { Valencia, Luis de } \\
\text { Cordero, Rodrigo }\end{array}$ & Mercader & $\begin{array}{l}\text { Zamora } \\
\text { Vigo }\end{array}$ & $\begin{array}{l}\mathrm{SD} \\
\mathrm{SD}\end{array}$ & $\begin{array}{l}\text { Comisión por } \\
\text { carga }\end{array}$ & O.M. & 12 & Sí \\
\hline
\end{tabular}




\begin{tabular}{|c|c|c|c|c|c|c|c|c|}
\hline 1595 & $\begin{array}{l}\text { Valencia, Luis de } \\
\text { Villalpando, Antonio }\end{array}$ & Mercader & $\begin{array}{l}\text { Zamora } \\
\text { Bayona }\end{array}$ & $\begin{array}{l}\mathrm{LN} \\
11.000\end{array}$ & $\begin{array}{c}3 / 5 \\
2 / 5 \text { y } 1 / 5\end{array}$ & Pescado, azúcar & 12 & Sí \\
\hline 1595 & $\begin{array}{l}\text { Rodríguez Montesinos, Fco. } \\
\text { Pérez de la Plaza, Esteban }\end{array}$ & $\begin{array}{l}\text { Mercader } \\
\text { Mercader }\end{array}$ & $\begin{array}{l}\text { Zamora } \\
\text { Coria }\end{array}$ & $\begin{array}{l}8.800 \\
5.500\end{array}$ & $\begin{array}{l}1 / 2 \\
1 / 2\end{array}$ & Aceite, O.M. & 4 & Sí \\
\hline 1596 & $\begin{array}{l}\text { Valencia, Luis de } \\
\text { Villalpando, Antonio }\end{array}$ & Mercader & $\begin{array}{l}\text { Zamora } \\
\text { Zamora }\end{array}$ & $\begin{array}{l}\text { LN } \\
11.000\end{array}$ & $\begin{array}{l}2 / 5 \text { y } 1 / 4 \\
3 / 5 \text { y } 3 / 4\end{array}$ & $\begin{array}{l}\text { Pescado, cera, } \\
\text { azúcar, «Bra- } \\
\text { sil», plomo, } \\
\text { campanil }\end{array}$ & 12 & Sí \\
\hline 1596 & $\begin{array}{l}\text { López, Bernardo } \\
\text { López de Araúxo, Antonio }\end{array}$ & Mercader & $\begin{array}{l}\text { Zamora } \\
\text { Vigo }\end{array}$ & $\begin{array}{l}\mathrm{LN} \\
7.000\end{array}$ & $\begin{array}{l}3 / 5 \\
2 / 5\end{array}$ & Pescado, OM & 12 & Sí \\
\hline 1596 & $\begin{array}{l}\text { Villalpando, Fco de } \\
\text { Pérez, Juan }\end{array}$ & & $\begin{array}{l}\text { Zamora } \\
\text { Pontevedra }\end{array}$ & $\begin{array}{c}3.500+\mathrm{LN} \\
1.500\end{array}$ & $\begin{array}{l}3 / 5 \\
2 / 5\end{array}$ & Pescado, O.M. & 10 & Sí \\
\hline 1597 & $\begin{array}{l}\text { Valencia, Luis de } \\
\text { Acayna, Fdo de }\end{array}$ & Mercader & $\begin{array}{l}\text { Zamora } \\
\text { Pontevedra }\end{array}$ & $\begin{array}{l}\mathrm{LN} \\
5.500\end{array}$ & & Pescado, O.M. & 12 & Sí \\
\hline 1597 & $\begin{array}{l}\text { Valencia, Luis de } \\
\text { Rojas, Catalina de (viuda de } \\
\text { Villalpando, Antonio de) } \\
\text { Peña, Cristóbal de la (yerno) }\end{array}$ & Mercader & $\begin{array}{l}\text { Zamora } \\
\text { Bayona } \\
\text { Bayona }\end{array}$ & $\begin{array}{l}\text { SD } \\
\text { SD } \\
\text { SD } \\
\text { SD }\end{array}$ & $\begin{array}{c}3 / 5,4 / 5,2 / 3 \\
\\
2 / 5,1 / 5 \text { y } 1 / 3 \\
\text { (entre los dos) }\end{array}$ & $\begin{array}{l}\text { Pescado, azú- } \\
\text { car, cera, cereal, } \\
\text { cueros, vino, } \\
\text { O.M. }\end{array}$ & 12 & $\begin{array}{l}\text { Sí } \\
\text { No }\end{array}$ \\
\hline 1597 & $\begin{array}{l}\text { Maniego, Antonio } \\
\text { Rodríguez Montesino, Fco }\end{array}$ & $\begin{array}{l}\text { Escribano/ } \\
\text { mercader }\end{array}$ & $\begin{array}{l}\text { Morales } \\
\text { Zamora }\end{array}$ & 7.300 & $\begin{array}{l}1 / 2 \\
1 / 2\end{array}$ & $\begin{array}{l}\text { Gualda, cardón. } \\
\text { O.M }\end{array}$ & 6 & No \\
\hline
\end{tabular}




\begin{tabular}{|c|c|c|c|c|c|c|c|c|}
\hline 1598 & $\begin{array}{l}\text { Sánchez, Bartolomé } \\
\text { Alonso Lagartero, Francisco } \\
\text { Guerra, María (matrim.) }\end{array}$ & Mercader & $\begin{array}{l}\text { Zamora } \\
\text { Zamora } \\
\text { Zamora }\end{array}$ & $\begin{array}{r}8.800 \\
\mathrm{SD} \\
\mathrm{SD}\end{array}$ & $\begin{array}{l}1 / 3 \\
1 / 3 \\
1 / 3\end{array}$ & Tratos lícitos & 12 & $\begin{array}{l}\text { No } \\
\text { Sí } \\
\text { No }\end{array}$ \\
\hline 1598 & $\begin{array}{l}\text { Vázquez, Francisco } \\
\text { Dorreyno, Esteban }\end{array}$ & & $\begin{array}{l}\text { Zamora } \\
\text { Pontevedra }\end{array}$ & $\begin{array}{l}6.600 \\
3.300\end{array}$ & $\begin{array}{l}2 / 3 \\
1 / 3\end{array}$ & Pescado, O.M. & 12 & $\begin{array}{l}\text { Sí } \\
\text { Sí }\end{array}$ \\
\hline 1598 & $\begin{array}{l}\text { Villacorta, Antonio de (El } \\
\text { Mozo) } \\
\text { Alonso Lagartero, Francisco } \\
\text { González de Silva, Alonso }\end{array}$ & $\begin{array}{l}\text { Mercader } \\
\text { Mercader }\end{array}$ & $\begin{array}{l}\text { Zamora } \\
\text { Zamora } \\
\text { Zamora }\end{array}$ & $\begin{array}{l}9.000 \\
4.000\end{array}$ & $\begin{array}{l}1 / 3 \\
1 / 3\end{array}$ & Pescado & 9 & $\begin{array}{l}\text { Sí } \\
\text { Sí }\end{array}$ \\
\hline 1599 & $\begin{array}{l}\text { Tapia de Vargas, Ldo. Anto- } \\
\text { nio de } \\
\text { Hernández, Antonio }\end{array}$ & $\begin{array}{l}\text { Ldo / clérigo } \\
\text { Lencero }\end{array}$ & $\begin{array}{l}\text { Estante en } \\
\text { Zamora } \\
\text { Zamora }\end{array}$ & 1.741 & $\begin{array}{l}2 / 3 \\
1 / 3\end{array}$ & Lienzos & 1 & $\begin{array}{l}\text { Sí } \\
\text { Sí }\end{array}$ \\
\hline 1599 & $\begin{array}{l}\text { Rojas, Catalina de (Viuda de } \\
\text { Antonio de Villalpando) } \\
\text { Valencia, Luis de }\end{array}$ & $\begin{array}{l}\text { Mercader } \\
\text { Mercader }\end{array}$ & $\begin{array}{l}\text { Bayona } \\
\text { Zamora }\end{array}$ & 3.000 & $\begin{array}{l}2 / 5,1 / 5 \text { y } 1 / 4 \\
3 / 5 \text { y } 4 / 5\end{array}$ & $\begin{array}{l}\text { Pescado, azú- } \\
\text { car, cera }\end{array}$ & 12 & 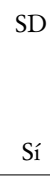 \\
\hline 1599 & $\begin{array}{l}\text { Díez, Francisco } \\
\text { Vergas, Jerónimo de } \\
\text { Sánchez, Antonio }\end{array}$ & & $\begin{array}{l}\text { Zamora } \\
\text { Zamora } \\
\text { Zamora }\end{array}$ & & $\begin{array}{l}1 / 3 \\
1 / 3 \\
1 / 3\end{array}$ & Vino & 12 & $\begin{array}{l}\text { Sí } \\
\text { Sí }\end{array}$ \\
\hline
\end{tabular}




\begin{tabular}{|c|c|c|c|c|c|c|c|c|}
\hline 1599 & $\begin{array}{l}\text { Villalpando, Francisco } \\
\text { Maestresala, Juan } \\
\text { Pando Portillo, Manuel (hijo } \\
\text { de Francisco) }\end{array}$ & & $\begin{array}{l}\text { Zamora } \\
\text { Bayona } \\
\text { Zamora }\end{array}$ & $\begin{array}{c}1.100+\mathrm{LN} \\
3.000\end{array}$ & $\begin{array}{l}3 / 6 \\
2 / 6 \\
1 / 6\end{array}$ & Pescado & 12 & $\begin{array}{l}\text { Sí } \\
\text { Sí } \\
\text { SD }\end{array}$ \\
\hline 1599 & $\begin{array}{l}\text { Alonso Lagartero, Francisco } \\
\text { Gómez, Martín }\end{array}$ & $\begin{array}{l}\text { Mercader } \\
\text { Mercader }\end{array}$ & $\begin{array}{l}\text { Zamora } \\
\text { Bayona }\end{array}$ & $\begin{array}{l}\mathrm{LN} \\
3.000\end{array}$ & $\begin{array}{l}3 / 5 \\
2 / 5\end{array}$ & Pescado & 12 & $\begin{array}{l}\text { Sí } \\
\text { Sí }\end{array}$ \\
\hline 1599 & $\begin{array}{l}\text { García de Losada, Hernán } \\
\text { Gumiel, Pedro de }\end{array}$ & Mercader & $\begin{array}{l}\text { Zamora } \\
\text { Zamora } \\
\end{array}$ & $4.000+\mathrm{LN}$ & $\begin{array}{l}2 / 3 \\
1 / 3 \\
\end{array}$ & $\begin{array}{l}\text { Pescado, azú- } \\
\text { car, O.M. }\end{array}$ & 12 & $\begin{array}{l}\text { Sí } \\
\text { Sí }\end{array}$ \\
\hline 1599 & $\begin{array}{l}\text { Toro, Catalina de } \\
\text { Monzón, Diego de }\end{array}$ & & $\begin{array}{l}\text { Zamora } \\
\text { Carbajales }\end{array}$ & 1.100 & $\begin{array}{l}1 / 2 \\
1 / 2 \\
\end{array}$ & «Mercadurías» & SD & $\begin{array}{l}\text { SD } \\
\text { Sí }\end{array}$ \\
\hline 1599 & $\begin{array}{l}\text { Cedrón, Juan } \\
\text { Hernández, Luis }\end{array}$ & & $\begin{array}{l}\text { Zamora } \\
\text { Arcenillas }\end{array}$ & $\begin{array}{l}1 / 2 \\
1 / 2\end{array}$ & $\begin{array}{l}1 / 2 \\
1 / 2 \\
\end{array}$ & Vino & 12 & $\begin{array}{l}\text { No } \\
\text { No }\end{array}$ \\
\hline 1600 & $\begin{array}{l}\text { Álvarez, Beatriz (Vda. de } \\
\text { Valencia, Luis de) } \\
\text { Pérez, Alonso }\end{array}$ & & $\begin{array}{l}\text { Zamora } \\
\text { La Guardia }\end{array}$ & LQP & $3 / 5$ & Pescado, O.M. & 12 & No \\
\hline 1600 & $\begin{array}{l}\text { Vergas, Jerónimo de } \\
\text { López de Araujo, Antonio }\end{array}$ & & $\begin{array}{l}\text { Zamora } \\
\text { Vigo }\end{array}$ & $\begin{array}{l}4.000 \\
5.000\end{array}$ & $\begin{array}{l}\text { SD } \\
\text { SD }\end{array}$ & $\begin{array}{l}\text { Pescado, cera, } \\
\text { «Brasil», azú- } \\
\text { car, O.M. }\end{array}$ & 12 & $\begin{array}{l}\text { Sí } \\
\text { Sí }\end{array}$ \\
\hline 1600 & $\begin{array}{l}\text { Villalobos, Matías } \\
\text { Herrera, Juan }\end{array}$ & Sedero & $\begin{array}{l}\text { Zamora } \\
\text { Zamora }\end{array}$ & 940 (entre ambos) & $\begin{array}{l}1 / 2 \\
1 / 2\end{array}$ & Vino & 3 & $\begin{array}{l}\text { Sí } \\
\text { Sí }\end{array}$ \\
\hline 1600 & $\begin{array}{l}\text { Vergas, Domingo de } \\
\text { Vergas, Jerónimo de }\end{array}$ & & $\begin{array}{l}\text { Zamora } \\
\text { Zamora }\end{array}$ & 22.000 & $\begin{array}{l}1 / 3 \\
2 / 3\end{array}$ & $\begin{array}{l}\text { Azúcar, pes- } \\
\text { cado, especias, } \\
\text { «Brasil», O.M. }\end{array}$ & 24 & $\begin{array}{l}\text { Sí } \\
\text { Sí }\end{array}$ \\
\hline
\end{tabular}




\begin{tabular}{|c|c|c|c|c|c|c|c|c|}
\hline 1600 & $\begin{array}{l}\text { Alonso Lagartero, Francisco } \\
\text { Dorreyno, Esteban }\end{array}$ & $\begin{array}{l}\text { Mercader } \\
\text { Mercader }\end{array}$ & $\begin{array}{l}\text { Zamora } \\
\text { Pontevedra }\end{array}$ & $\begin{array}{c}8.000+\mathrm{LN} \\
4.000\end{array}$ & $\begin{array}{l}2 / 3 \\
1 / 3\end{array}$ & Pescado, O.M. & 12 & Sí \\
\hline 1600 & $\begin{array}{l}\text { Alonso Lagartero, Francisco } \\
\text { Gómez, Martín }\end{array}$ & $\begin{array}{l}\text { Mercader } \\
\text { Mercader }\end{array}$ & $\begin{array}{l}\text { Zamora } \\
\text { Bayona }\end{array}$ & $\begin{array}{l}\mathrm{LN} \\
3.000\end{array}$ & $\begin{array}{l}3 / 5 \\
2 / 5\end{array}$ & Pescado, O.M. & 12 & Sí \\
\hline 1600 & $\begin{array}{l}\text { Tapia de Vargas, Ldo. Anto- } \\
\text { nio de } \\
\text { Núñez, Gaspar } \\
\text { Herrera, Luisa (matrim.) }\end{array}$ & $\begin{array}{l}\text { Ldo/ Clérigo } \\
\text { Especiero }\end{array}$ & $\begin{array}{l}\text { Zamora } \\
\text { Zamora } \\
\text { Zamora }\end{array}$ & 1.000 & $2 / 3$ & Especiería & 12 & $\begin{array}{l}\text { Sí } \\
\text { No }\end{array}$ \\
\hline 1600 & $\begin{array}{l}\text { García Losada, Hernán } \\
\text { Cordero, Rodrigo }\end{array}$ & $\begin{array}{l}\text { Mercader } \\
\text { Mercader }\end{array}$ & $\begin{array}{l}\text { Zamora } \\
\text { Vigo }\end{array}$ & $\begin{array}{c}5.000+\mathrm{LN} \\
4.000\end{array}$ & $\begin{array}{l}2 / 3 \\
1 / 3\end{array}$ & $\begin{array}{l}\text { Pescado, azú- } \\
\text { car, O.M. }\end{array}$ & 12 & Sí \\
\hline 1600 & $\begin{array}{l}\text { Valencia, Luis de (hijos) } \\
\text { Vergas, Domingo de }\end{array}$ & Mercader & $\begin{array}{l}\text { Zamora } \\
\text { Zamora }\end{array}$ & $\begin{array}{l}\text { LN } \\
16.500\end{array}$ & $\begin{array}{l}\text { SD } \\
\text { SD }\end{array}$ & $\begin{array}{l}\text { Azúcar, «Bra- } \\
\text { sil», cera, OM }\end{array}$ & 6 & Sí \\
\hline
\end{tabular}

Abreviaturas: Cat. $=$ Categoría; Fco. $=$ Francisco; $\mathrm{LN}=$ Lo necesario o lo que fuere menester; $\mathrm{LQP}=\mathrm{Lo}$ que pueda; $\mathrm{SD}=\mathrm{Sin}$ determinar; Matrim.= matrimonio; O.M.= Otras mercancías; Vda.= Viuda. 